\title{
w-MPS Risk Aversion and the Shadow CAPM: Theory and Empirical Evidence
}

\author{
Lin Huang ${ }^{\dagger}$ \\ Southwestern University of Finance and Economics \\ China \\ Chenghu Ma \\ Fudan University \\ China \\ and \\ Hiroyuki Nakata \\ University of Leicester, UK and \\ Research Institute of Economy, Trade and Industry, Japan
}

\footnotetext{
* We gratefully acknowledge the comments of participants in the 2013 Asian Meeting of the Econometric Society, the 2014 IABPAD Winter Conference, and 2015 International Conference on Quantitative Finance at Beijing University. Many thanks to seminar participants who have commented on earlier versions of this paper, titled "Mean-Preserving-Spread Risk Aversion and the Shadow CAPM: An Empirical Study". We have benefited from conversation with Yacine AitSahalia, Michael Brennan, Phil Dybvig, Richard Harris, Emmanuel Haven, Jun Liu, and Xiaoquan Liu. And special thanks to the editor Chris Adcock and an anonymous referee for the invaluable comments that helped us improve our paper. Ma acknowledge support from Chinese Natural Science Foundation under grant \#71271058.

${ }^{\dagger}$ Correspondence: Lin Huang, Research Institute of Economics and Management, Southwestern University of Finance and Economics, 55 Guanghuacun Street, Chengdu, China 610074. Tel: +86-28-87352039; Email:Ihuang@swufe.edu.cn.
} 


\title{
w-MPS Risk Aversion and the Shadow CAPM: Theory and Empirical Evidence
}

\begin{abstract}
This paper presents the shadow Capital Asset Pricing Model (CAPM) of Ma (2011a) as an intertemporal equilibrium asset pricing model, and tests it empirically. In contrast to the classical CAPM - a single factor model based on a strong behavioral or distributional assumption, the shadow CAPM can be represented as a two factor model, and only requires a modest behavioral assumption of weak form mean-preserving spread (w-MPS) risk aversion. The empirical tests provide support in favor of the shadow CAPM over the classical CAPM, the Consumption CAPM, or the Epstein and Zin (1991) model. Moreover, the shadow CAPM provides a consistent explanation for the cross-sectional variations of expected returns on the stocks and for the time-varying equity premium.
\end{abstract}

JEL Classification Code: G12, G11

Keywords: equity premium, w-MPS risk aversion, recursive utility, shadow price 


\section{Introduction}

In the asset pricing literature, CAPM and Consumption CAPM (CCAPM), two of the most famous asset pricing models, do not receive empirical support unfortunately. Existing empirical studies have shown two key observations that the CAPM or the CCAPM fails to explain: (a) the equity premium is higher at business cycle troughs than at peaks (i.e. countercyclical equity premium), and (b) there is a systematic risk premium for small stocks to stocks with high market capitalization (i.e. the size effect) reported for instance by Campbell (1987), Campbell and Shiller (1988b), Fama and French (1988, 1989), and Keim and Stambaugh (1986). To be able to explain these two features in a systematic way, we therefore need to relax the assumptions made in the CAPM or the CCAPM.

One such early effort can be found in Epstein and Zin (1991), who developed a testable, representative agent, intertemporal equilibrium asset pricing model based on Epstein and Zin's (1989) recursive utility. An Epstein and Zin's recursive utility nests the expected utility with a constant relative risk aversion, whilst it allows for the separation of the elasticity of intertemporal substitution (EIS) from relative risk aversion. ${ }^{1}$ Yogo (2006) furthers this line of research by incorporating durable consumption in addition to the standard nondurable consumption in the model.

Ma (2011a) meanwhile extends Epstein and Zin (1991) in a different direction than Yogo (2006). Rather than introducing durable consumption, he relaxes the assumption on the functional form of the certainty equivalent (CE). Ma (2011a) merely introduces the following qualitative behavioral axiom, called weak form mean-preserving spread (wMPS) risk aversion. Namely, $X$ is preferred to $Y$, if $Y$ is a mean-preserving spread (MPS) of $X$ in the sense of $Y=X+\varepsilon, \operatorname{Cov}(X, \varepsilon)=0$ and $\mathbb{E}[\varepsilon]=0 .^{2}$ The assumption of wMPS risk aversion is appealing because, first, it captures investor's psycho-logical aversion

\footnotetext{
${ }^{1}$ The EIS is known to characterize intertemporal choice of the agent, which plays a key role in determining the agent's savings behavior (see Hall, 1988).

${ }^{2}$ The notion of w-MPS risk aversion is introduced by Boyle and Ma (2013). They show that w-MPS risk aversion constitutes the key behaviorial assumption for the validity of the static CAPM. Ma (2011b) extends the analysis to continuous time, and studies the sequential portfolio choice problem to investors displaying w-MPS risk aversion.
} 
towards "increase in risk" in a natural way; second, w-MPS risk averse preferences are not restricted to certain classes of expected or non-expected utility functions. Therefore, they are not subject to criticisms such as the well-known Allais Paradox and other deficiencies associated with expected utility functions. The expected utility certainty equivalent as assumed in Epstein and Zin (1991) is a special case of Ma's (2011a) formulation.

With the assumption of w-MPS risk aversion, Ma (2011a) formally derived the following (shadow) risk-return relationship called the shadow CAPM for a Lucas (1978) "tree" model (with a stationary Markov information structure): For every asset $j$,

$$
\mathbb{E}_{t}\left[\widehat{R}_{t+1}^{j}\right]=R_{t}^{f}+\alpha_{\Lambda, t}^{j}\left(\mathbb{E}_{t}\left[\widehat{R}_{t+1}^{m}\right]-R_{t}^{f}\right), \quad \forall t
$$

where $\widehat{R}_{t}^{j}$ is the shadow return of asset $j$, with $m$ indicating the market portfolio as in the CAPM. Equation (1) clearly resembles the CAPM. It is, however, expressed in terms of the shadow return $\widehat{R}_{t}^{j}:=R_{t}^{j} \Lambda_{t} / \mathbb{E}\left[\Lambda_{t}\right]$, i.e., obtained from the asset return scaled by a normalized stochastic shadow price $\Lambda_{t} / \mathbb{E}_{[}\left[\Lambda_{t}\right]$. Note that the shadow price $\Lambda_{t}$ may be stochastic, and the shadow CAPM reduces to the CAPM when asset returns are i.i.d. and/or the shadow price $\Lambda_{t}$ is deterministic for all $t$. Moreover, Ma (2011a) showed that the shadow price $\Lambda_{t}$ can be expressed as a function of the wealth-dividend ratio. Since market returns are widely reported to be non-i.i.d. (for instance, Campbell, Lo and Mackinlay 1997), and the $\mathrm{P} / \mathrm{D}$ ratio for the aggregate equity is stochastic (for instance, Shiller 2005), the shadow price $\Lambda_{t}$ would be stochastic, which in turn would provide support for the shadow CAPM over the CAPM.

With this background, this paper tests the shadow CAPM of Ma (2011a) empirically. In doing so, we present three econometric models of the shadow CAPM: (a) one based on the Euler equation, (b) the unconditional linear factor model, and (c) the conditional linear factor model. As a factor model, the shadow CAPM is shown to be a two factor model, where a preference parameter, namely the EIS parameter, is included in the model indirectly alongside the two key factors - the wealth-dividend ratio and the return on the market portfolio. We find that the estimate of the EIS parameter is largely consistent with 
the results documented in the empirical macroeconomics literature e.g. Attanasio and Weber (1989), Vissing-Jorgensen (2002), Bansal and Yaron (2004), and Guvenen (2006). Also, the linear factor versions of the shadow CAPM outperform the CAPM, the CCAPM with power utility (Breeden, 1979; Breeden and Litzenberger, 1978; Rubinstein, 1976) and the Epstein-Zin's (1991) model. The findings that the shadow CAPM performs better than the Epstein-Zin's model support the w-MPS risk aversion assumption in certainty equivalent. The shadow CAPM is marginally outperformed by Fama and French's (1993) three-factor model, however. Moreover, the shadow CAPM is largely consistent with the two observations above, i.e. the countercyclical equity premium and the size effect. Thus, this paper adds to the extensive literature on consumption-based explanations for these two phenomena such as Bansal et al. (2005), Yogo (2006), Kang et al. (2011), and Xiao et al. (2013).

The intuition for the countercyclical equity premium under the shadow CAPM is as follows. The conditional covariance between excess stock returns and the wealth-dividend ratio is procyclical, since the consumption growth rate and dividend growth rate are less volatile than the market prices (see, for instance, Campbell, 1999); thus, when the economy is expanding, the wealth-dividend ratio would be high relative to its conditional mean, and the conditional covariances between the wealth-dividend ratio and stock returns are high. With a negative risk price for the wealth-dividend ratio, the equity premium would be countercyclical. This finding is similar to Santos and Veronesi (2006) and Duffee (2005)'s "composition effect" that brings countercyclicality. The composition effect is first made clear by Santos and Veronesi (2006), in an examination of the relative importance of labor income to consumption. Duffee (2005) found that when wealth consists of stock market wealth and all other assets such as human capital, and when stock market wealth is high relative to consumption, both the conditional covariance and correlation are high, while the relationship between expected excess returns and the conditional covariance is negative. Other consumption-based models also try to explain the counter-cyclicality. For example, Yogo (2006) finds that the equity premium is countercyclical because the covariance of stock returns with durable consumption growth is countercyclical. Li (2006) 
shows that in Campbell and Cochrane's (1999) habit formation model, it is the countercyclical market price of risk, not the countercyclical variation of risk aversion that drives the risk premium. Constantinides and Ghosh (2014) have recently presented evidence that the countercyclical household consumption growth play a major role in driving asset prices.

As for the size effect, small stocks have more risk exposure measured by the covariance with the price-dividend ratio than large stocks do. It follows that the conditional covariance of the small stocks are more procyclical. This procyclical property explains the higher average returns for small stocks. In the literature, several papers have related the size anomaly to the consumption risks. Bansal et al. (2005) use the aggregate consumption risk reflected in cash flow to account for the return difference in size-sorted portfolios. Similarly as Lettau and Ludvigson (2001), Kang et al. (2011) use the detrend macroeconomic variables to show that small stocks have higher consumption beta than large stocks do. Xiao et al. (2013) explain the size effect using the innovations in future consumption growth, they find that the beta with news about consumption growth have a greater impact on small portfolios.

The rest of the paper is organized as follows. Section 2 gives a brief introduction of the shadow CAPM. In section 3, we present three econometric specifications of the shadow CAPM - (a) one based on its Euler equation, (b) the unconditional linear factor model, and (c) the conditional linear factor model. Section 4 reports the estimation results under the three specifications. Finally, section 5 concludes the paper.

\section{The Shadow CAPM}

In this section, we shall explain the structure of the shadow CAPM. The shadow CAPM is based on the assumption that there exists an infinitely lived representative agent in the Lucas (1978) "tree" model with a Markov information structure. There are a finite number of risky assets, in addition to a risk free asset, available for trading. The representative 
agent solves the standard optimizing consumption portfolio choice problem by selecting a consumption-portfolio bundle to maximize the utility subject to the sequential flow budget constraints. The equilibrium price is obtained as a solution to the market clearing condition in this representative agent economy.

The representative agent's preference over the consumption stream $\mathbf{c}=\left\{c_{t}\right\}_{t \in(0,1, \ldots)}$ is summarized by Epstein and Zin's (1989) recursive utility of the form

$$
U_{t}(\mathbf{c})=H\left(c_{t}, \mathrm{CE}\left[U_{t+1}(\mathbf{c}) \mid \mathcal{F}_{t}\right]\right)
$$

where $H(c, v)$ is called the utility aggregator, and $\mathrm{CE}\left[\cdot \mid \mathcal{F}_{t}\right]$ is the certainty equivalent that ranks future utility $U_{t+1}(\mathbf{c})$ conditional on the current information $\mathcal{F}_{t}$.

In this paper, we consider recursive utility generator with a constant elasticity of intertemporal substitution

$$
H(c, v)=\left(c^{\rho}+\beta v^{\rho}\right)^{1 / \rho}, \quad \rho<1 \text { and } \rho \neq 0,
$$

where parameter $\rho$ measures the degree of intertemporal substitution with elasticity of intertemporal substitution (EIS) given by $\psi=1 /(1-\rho)$, and a homothetic certainty equivalent

$$
C E\left[\eta x \mid \mathcal{F}_{t}\right]=\eta C E\left[x \mid \mathcal{F}_{t}\right], \quad \forall \eta, t
$$

The certainty equivalent is assumed to display weak form MPS risk aversion in the sense that for every $X$,

$$
\mathrm{CE}[X] \geq \mathrm{CE}[X+\varepsilon], \quad \text { with } \mathbb{E}[\varepsilon]=0 \text { and } \operatorname{Cov}(X, \varepsilon)=0 \text {. }
$$

As we shall see below, w-MPS risk aversion constitutes the key behavioral assumption for the shadow CAPM.

A detail derivation of the shadow CAPM is provided in Appendix A. The value function for the representative agent in this particular economy of Markov uncertainty is linear in 
the initial wealth $V_{t}=\Lambda_{t} W_{t}$, and the shadow price $\Lambda_{t}$ measures the sensitivity of agent's utility with respect to change in wealth. Also, future investment opportunity affects the agent's current portfolio through the shadow price. In particular, $\Lambda_{t}$ admits an analytic expression in terms of the wealth-dividend ratio, denoted as $K_{t}$. We have $\Lambda_{t}=K_{t}^{(1-\rho) / \rho}$ in equilibrium. ${ }^{3}$

As illustrated in Appendix A, w-MPS risk aversion implies that representative agent's optimal portfolio must belong to the so-called shadow efficient frontier - an efficient frontier derived from shadow asset returns $\widehat{R}_{t+1}^{j}$ for all tradable assets $j$, where $\widehat{R}_{t+1}^{j}:=$ $R_{t+1}^{j} \Lambda_{t+1} / \mathbb{E}_{t}\left[\Lambda_{t+1}\right]$. As a result, following the standard arguments of Markowitz's (1959) mean-variance analysis, we obtain the following dynamic equilibrium asset pricing model in discrete time, which we shall call the shadow CAPM. ${ }^{4}$ For every asset $j$,

$$
\mathbb{E}_{t}\left[\widehat{R}_{t+1}^{j}\right]=R_{t}^{f}+\alpha_{\Lambda, t}^{j}\left(\mathbb{E}_{t}\left[\widehat{R}_{t+1}^{m}\right]-R_{t}^{f}\right), \quad \forall t,
$$

where $\alpha_{\Lambda, t}^{j}=\frac{\operatorname{Cov}_{t}\left(\widehat{R}_{t+1}^{m} \widehat{R}_{t+1}^{j}-\widehat{R}_{t+1}^{f}\right)}{\operatorname{Cov}\left(\widehat{R}_{t+1}^{m}-\widehat{R}_{t+1}^{f}, \widehat{R}_{t+1}^{m}\right)}$.

If we express the LHS of shadow CAPM equation (4) in the form of excess returns instead of shadow returns with $\mathbb{E}_{t}\left[\widehat{R}_{t+1}^{j}\right]=\operatorname{Cov}_{t}\left(\Lambda_{t+1}, R_{t+1}^{j}\right) / \mathbb{E}_{t}\left[\Lambda_{t+1}\right]+\mathbb{E}_{t}\left[R_{t+1}^{j}\right]=-\gamma_{\Lambda, t}^{j}+$ $\mathbb{E}_{t}\left[R_{t+1}^{j}\right]$, the shadow-CAPM can be rewritten in terms of a two-factor risk premium decomposition: For every asset $j$,

$$
\begin{aligned}
\mathbb{E}_{t}\left[R_{t+1}^{j}\right]-R_{t}^{f}= & \alpha_{\Lambda, t}^{j}\left(\mathbb{E}_{t}\left[R_{t+1}^{m}\right]-R_{t}^{f}-\gamma_{\Lambda, t}^{m}\right)+\gamma_{\Lambda, t}^{j}, \quad \forall t \\
\text { where } \gamma_{\Lambda, t}^{j}:= & -\operatorname{Cov}_{t}\left(\Lambda_{t+1}, R_{t+1}^{j}\right) / \mathbb{E}_{t}\left[\Lambda_{t+1}\right]
\end{aligned}
$$

As noted above, the shadow CAPM reduces to the classical CAPM when $\Lambda$ is deterministic as is the case when asset returns are i.i.d. From equation (5), we can also see that, there are two sources of systematic risks towards the equity premium: The premium associated

\footnotetext{
${ }^{3}$ We may also interpret $K_{t}$ as wealth-consumption ratio or price-dividend ratio. In this theoretical setup, we make no distinction between the two. Nevertheless, we recognize that such distinction can be a matter of relevance in conducting empirical test of the model. This issue will be discussed in section 4 .

${ }^{4}$ We note that the shadow return of the market portfolio is in general correlated with the shadow return of the risk-free asset. As a consequence, the shadow risk-premium is proportional to $\alpha_{\Lambda}^{j}$, instead of $\beta_{\Lambda}^{j}$.
} 
with the market risk measure by $\alpha_{\Lambda, t}^{j}$ in the first term, and the price of the shadow risk given by $\gamma_{\Lambda, t}^{j}$ in the second term of the equation. So, it is the presence of the shadow risk that enables us to distinguish the shadow CAPM from the CAPM.

The shadow risk is typically non-negligible. It lies on the empirical evidence supporting the stochastic property of the wealth-dividend ratio. Moreover, the existence of the shadow premium $\gamma_{\Lambda, t}^{j}$ is potentially useful in explaining the time-varying equity premium - in particular, by capturing the part of the equity premium that cannot be explained by the market risk alone. Further empirical evidence will be discussed in section 4 .

\section{The Econometric Strategy}

\subsection{The Econometric Model of the Euler Equation}

In what follows, we explain how we can estimate the shadow CAPM using the generalized method of moments (GMM) approach of Hansen and Singleton (1982). We re-express the shadow CAPM equation (4) into a stochastic discount factor formulation. For every asset $j$, it must be true that

$$
1=A_{t} \mathbb{E}_{t}\left[\left(K_{t+1}\right)^{q} R_{t+1}^{j}\right]+B_{t} \mathbb{E}_{t}\left[\left(K_{t+1}\right)^{2 q} R_{t+1}^{m} R_{t+1}^{j}\right], \quad \forall t
$$

where

$$
\left[\begin{array}{c}
A_{t} \\
B_{t}
\end{array}\right]=\left[\begin{array}{cc}
\mathbb{E}_{t}\left[\left(K_{t+1}\right)^{q}\right] & \mathbb{E}_{t}\left[\left(K_{t+1}\right)^{2 q} R_{t+1}^{m}\right] \\
\mathbb{E}_{t}\left[\left(K_{t+1}\right)^{q} R_{t+1}^{m}\right] & \mathbb{E}_{t}\left[\left(\left(K_{t+1}\right)^{q} R_{t+1}^{m}\right)^{2}\right]
\end{array}\right]^{-1}\left[\begin{array}{c}
1 / R_{t}^{f} \\
1
\end{array}\right],
$$

with $q=(1-\rho) / \rho$. The detail derivation is provided in Appendix B.

Note that by estimating $q$, we can estimate the EIS parameter $\psi$ and its asymptotic standard error, since $\psi=(1+q) / q$. It follows that we may test the validity of the shadow CAPM by examining if the estimate of the EIS parameter $\psi$ is within the range that is shown to be reasonable by existing studies. 
However, the shadow CAPM equation (6) is a nonlinear function of the parameter $q$, and $q$ appears both at the numerator and denominator of $A_{t}$ and $B_{t}$. To simplify the estimation process and let the estimated results more reliable, we calculate the logarithmic counterpart for each item in equation (6) by following Campbell and Shiller (1988a). ${ }^{5}$ For notational simplicity, for random variable $X$, we use lowercase letter $x$ to indicate the log transform of $X$. Then, for every asset $j$,

$$
\begin{aligned}
\mathbb{E}_{t}\left[K_{t+1}^{q} R_{t+1}^{j}\right] \approx & 1+q \mathbb{E}_{t}\left[k_{t+1}\right]+\mathbb{E}_{t}\left[r_{t+1}^{j}\right] \\
& +\frac{1}{2} q^{2} \operatorname{Var}_{t}\left[k_{t+1}\right]+\frac{1}{2} \operatorname{Var}_{t}\left[r_{t+1}^{j}\right]+q \operatorname{Cov}_{t}\left(k_{t+1}, r_{t+1}^{j}\right), \\
\mathbb{E}_{t}\left[K_{t+1}^{2 q} R_{t+1}^{m} R_{t+1}^{j}\right] \approx & 1+2 q \mathbb{E}_{t}\left[k_{t+1}\right]+\mathbb{E}_{t}\left[r_{t+1}^{m}\right]+\mathbb{E}_{t}\left[r_{t+1}^{j}\right] \\
& +2 q^{2} \operatorname{Var}_{t}\left[k_{t+1}\right]+\frac{1}{2} \operatorname{Var}_{t}\left[r_{t+1}^{m}\right]+\frac{1}{2} \operatorname{Var}_{t}\left[r_{t+1}^{j}\right] \\
& +2 q \operatorname{Cov}_{t}\left(k_{t+1}, r_{t+1}^{m}\right)+2 q \operatorname{Cov}_{t}\left(k_{t+1}, r_{t+1}^{j}\right)+\operatorname{Cov}_{t}\left(r_{t+1}^{m}, r_{t+1}^{j}\right) .
\end{aligned}
$$

The expressions for $A_{t}$ and $B_{t}$ follow the same methodology. We assume further that the variances and covariances of asset returns and wealth-dividend ratios are homoskedastic. This allows us to use the sample variances and covariances of $k_{t}, r_{t}^{m}$, and $r_{t}^{j}$ in the estimation.

We still need to deal with the conditional expectations in the model. Following the treatment in the literature (see Ferson, et al 1987, Harvey 1989, Cochrane 1996 and many others), we use the scaling scheme. The scaling scheme includes scale returns and factors. For the general conditional stochastic discount factor (SDF) model of asset prices, $\mathbf{1}=\mathbb{E}\left[M_{t+1} \mathbf{R}_{t+1} \mid \mathcal{F}_{t}\right]$ holds, where $\mathbf{1}$ is a vector whose coordinates are all unity, $M_{t}$ is the $\mathrm{SDF}$, and $\mathbf{R}_{t}$ is the returns of the assets. In contrast, the scaling returns approach expands

${ }^{5}$ For positive and square-integrable random variables $\mathbf{X}=\left(X_{1}, X_{2}, \cdots, X_{n}\right)^{\top}$,

$$
E_{t}\left[X_{1}^{\alpha_{1}} \cdots X_{n}^{\alpha_{n}}\right]=E_{t}\left[e^{\boldsymbol{\alpha}^{\top} \mathbf{x}}\right] \approx 1+\boldsymbol{\alpha}^{\top} \boldsymbol{\mu}_{t}+\frac{1}{2} \boldsymbol{\alpha}^{\top} \Sigma_{t} \boldsymbol{\alpha}
$$

where $\boldsymbol{\alpha}:=\left(\alpha_{1}, \cdots, \alpha_{n}\right), \boldsymbol{\mu}_{t}$ is the vector of conditional expectation of $\mathbf{x}$, and $\Sigma_{t}$ is the conditional variance-covariance matrix of $\mathbf{x}$. The approximation is based on the second-order Taylor expansion around 0 . 
the set of returns to include the returns scaled by instruments, that is, we use the moment conditions

$$
\mathbb{E}\left[\mathbf{1} \otimes \mathbf{z}_{t}\right]=\mathbb{E}\left[M_{t+1}\left(\mathbf{R}_{t+1} \otimes \mathbf{z}_{t}\right)\right], \mathbf{z}_{t} \in \mathcal{F}_{t}
$$

where $\mathbf{z}_{t}$ is the instrumental variables and $\otimes$ denotes a Kronecker product. If $M$ is a linear combination of factors, i.e. $M=\mathbf{b}^{\top} \mathbf{f}$, where $\mathbf{f}$ are factors, then we can estimate the model by scaling factors with the form of $M_{t+1}=\mathbf{b}^{\top}\left(\mathbf{f}_{t+1} \otimes \mathbf{z}_{t}\right)$. We shall discuss the choices of instrumental variables in section 4.1.

\subsection{Linear Factor Model}

Furthermore, to make the shadow CAPM comparable with linear factor models, we follow the approach used in Yogo (2006) to approximate the shadow CAPM as a linear factor model. Suppose there are $L$ pricing factors $\mathbf{F}=\left(F_{1}, F_{2}, \cdots, F_{L}\right)$, such that

$$
-\frac{M_{t}}{\mathbb{E}\left[M_{t}\right]}=b_{0}+\mathbf{b}^{\top} \mathbf{F}_{t}
$$

A nonlinear $M_{t}$ can have a first-order log-linear approximation as follows:

$$
\frac{M_{t}}{\mathbb{E}\left[M_{t}\right]} \approx 1+m_{t}-\mathbb{E}\left[m_{t}\right]
$$

Let $\boldsymbol{\mu}_{F}=\mathbb{E}\left[\mathbf{F}_{t}\right]$ and $\boldsymbol{\Sigma}_{F j}=\mathbb{E}\left[\left(\mathbf{F}_{t}-\boldsymbol{\mu}_{F}\right)\left(R_{t}^{j}-R_{t}^{f}\right)\right]$. Then, $\mathbb{E}\left[M_{t}\left(R_{t}^{j}-R_{t}^{f}\right)\right]=0$ reduces to a linear factor model. ${ }^{6}$ For every asset $j$,

$$
\mathbb{E}\left[R_{t}^{j}-R_{t}^{f}\right]=\mathbf{b}^{\top} \boldsymbol{\Sigma}_{F j}
$$

Namely, the premium for asset $j$ is given by the price of risk $\mathbf{b}$ multiplied by the risk measure $\boldsymbol{\Sigma}_{F j}$.

\footnotetext{
${ }^{6}$ The linear factor model can be rewritten as a linear beta pricing model: For every asset $j$,

$$
E\left[R_{t}^{j}-R_{t}^{f}\right]=\boldsymbol{\lambda}^{\top} \boldsymbol{\beta}_{j},
$$

where $\boldsymbol{\lambda}=\boldsymbol{\Sigma}_{F F} \mathbf{b}$ is known as factor risk premium and $\boldsymbol{\beta}_{j}=\boldsymbol{\Sigma}_{F F}^{-1} \boldsymbol{\Sigma}_{F j}$ with $\boldsymbol{\Sigma}_{F F}=E\left[\left(\mathbf{F}_{t}-\boldsymbol{\mu}_{F}\right)\left(\mathbf{F}_{t}-\right.\right.$ $\left.\left.\boldsymbol{\mu}_{F}\right)^{\top}\right]$.
} 
Assume the SDF of the shadow CAPM can be approximately written as a linear factor model. By applying the above methodology, the corresponding unconditional linear factorization of equation (6) becomes

$$
\mathbb{E}\left[R_{t}^{j}-R_{t}^{f}\right]=b_{1} \operatorname{Cov}\left(r_{t}^{m}-r_{t}^{f}, R_{t}^{j}-R_{t}^{f}\right)+b_{2} \operatorname{Cov}\left(k_{t}, R_{t}^{j}-R_{t}^{f}\right),
$$

where coefficients $b_{1}$ and $b_{2}$ can be interpreted as the risk prices for the market portfolio and for the wealth-dividend ratio, respectively. Observe that differences in expected returns across assets must reflect the differences in the quantity of risk across assets, measured by the covariance between the asset's return and wealth-dividend ratio, i.e. $\operatorname{Cov}\left(k_{t}, R_{t}^{j}-R_{t}^{f}\right)$, in addition to the covariance between the asset's return and the market excess return, i.e. $\operatorname{Cov}\left(r_{t}^{m}-r_{t}^{f}, R_{t}^{j}-R_{t}^{f}\right)$.

\subsection{Conditional Linear Factor Model}

By construction, the shadow CAPM is based on conditional expectation. Thus, we need to take account the role of information. The conditional version of the multifactor shadow CAPM approximation would be expressed as follows: For every asset $j$,

$$
\mathbb{E}_{t}\left[R_{t+1}^{j}-R_{t+1}^{f}\right]=b_{1} \operatorname{Cov}_{t}\left(r_{t+1}^{m}-r_{t+1}^{f}, R_{t+1}^{j}-R_{t+1}^{f}\right)+b_{2} \operatorname{Cov}_{t}\left(k_{t+1}, R_{t+1}^{j}-R_{t+1}^{f}\right),
$$

where $\mathbb{E}_{t}[\cdot]$ is the conditional expectation at time $t$, and $\operatorname{Cov}_{t}(\cdot, \cdot)$ is covariance based on the conditional expectation $\mathbb{E}_{t}$. We see that time variations in expected returns must be explained by time variations in the quantity of risk, measured by the conditional covariance with the market excess returns and wealth-dividend ratios. Thus, the same set of variables that are used to predict excess returns must also predict the conditional covariances. 
Consider the following linear regression $\operatorname{model}^{7}$ : For every asset $j$,

$$
\begin{aligned}
R_{t+1}^{j}-R_{t+1}^{f} & =\left(\Pi^{j}\right)^{\top} \mathbf{z}_{t}+\epsilon_{t+1}^{j}, \quad \forall t, \\
\epsilon_{t+1}^{j} F_{l, t+1} & =\left(\Upsilon_{l}^{j}\right)^{\top} \mathbf{z}_{t}+\eta_{l, t+1}^{j}, \quad \forall l, t,
\end{aligned}
$$

where $\mathbf{z}_{t}$ is a vector of $I$ instruments. Note that equation (10) models the conditional mean of the excess returns, and equation (11) models the conditional covariance of excess returns with factors. There are $(N+N L) I \times 1$ total moment functions for $N$ portfolio returns, $L$ factors and $I$ instruments. When coefficients $\Pi$ and the covariance matrix $\Upsilon$ satisfy $\Pi=\sum_{l=1}^{L} b_{l} \Upsilon_{l}$, then the above model corresponds to the conditional version of equation $(7)$

$$
R_{t+1}^{j}-R_{t+1}^{f}=\left(\sum_{l=1}^{L} b_{l} \Upsilon_{l}\right)^{\top} \mathbf{z}_{t}+\epsilon_{t+1}^{j}
$$

The regression models (11) and (12) can be estimated through the moment functions in the GMM framework

$$
e=\left[\begin{array}{c}
\left(\mathbf{R}_{t+1}-R_{t+1}^{f} \mathbf{1}\right)-\left(\sum_{l=1}^{L} b_{l} \Upsilon_{l}\right)^{\top} \mathbf{z}_{t} \\
\operatorname{vec}\left(\left[\left(\mathbf{R}_{t+1}-R_{t+1}^{f} \mathbf{1}\right)-\left(\sum_{l=1}^{L} b_{l} \Upsilon_{l}\right)^{\top} \mathbf{z}_{t}\right] \mathbf{F}_{t+1}^{\top}\right)-\left(\Upsilon_{l}^{j}\right)^{\top} \mathbf{z}_{t}
\end{array}\right] \otimes \mathbf{z}_{t} .
$$

It follows that we can estimate risk prices $b_{1}$ and $b_{2}$ together with covariance matrix $\Upsilon$, while the model is overidentified by $N I-L$ degrees.

\section{Data and Estimation Results}

\subsection{Data}

We use the S\&P 500 index for the stock market data. The testing portfolios include the 25 Fama-French portfolios sorted by size and book-to-market equity, the ten portfolios

\footnotetext{
${ }^{7}$ The methodology described here has been used in Campbell (1987), Harvey (1989) and Yogo (2006).
} 
sorted by their market value (size) according to the same criteria as that used in Fama and French (1992). We also consider the six portfolios sorted by size and book-to-market equity, six portfolios sorted by size and momentum and ten portfolios sorted by industry in our robustness analysis. All of the portfolios are usually examined in the literature. The portfolios data are from Kenneth French's web page. These portfolios are on the New York Stock Exchange, the American Stock Exchange and NASDAQ stocks in Compustat.

For the instruments, we choose variables that are said to predict business cycles in the literature. While a number of variables may help forecast future economic conditions, following Cochrane (1996), we restrict the number of variables small in order to maintain the precision of the estimates of the parameters. More specifically, we use the following three different instruments with the dividend-price ratio separately: (a) Lettau and Ludvigson (2001)'s cay, ${ }^{8}$ (b) the term premium (yield on long-term government bonds less yield on 3-month Treasury bills) denoted by $T R M,{ }^{9}$ and (c) the default premium (yield between BAA corporate bonds and AAA corporate bonds) denoted by DEF. The cay data is from Lettau's web page. ${ }^{10}$ The term premium and the default premium data are from Federal Reserve Bulletin published by the Federal Reserve System. Scaling factors and returns by instruments can lead to an explosion of moment conditions and scaled factors. Similarly as Cochrane (1996), we only choose the first, second, fifth and tenth deciles as opposed to all ten deciles. The second, fifth and tenth deciles are used to capture the cross-sectional information in the original ten deciles. The first decile portfolio is also included in order to examine the well-known size anomaly.

We propose two different variables to represent the wealth-dividend ratio $K$ : GDPconsumption ratio $(\mathrm{GDP} / \mathrm{C})$ and the market's payoff-dividend ratio $(P+D) / D$. We use GDP/C, because in the Lucas tree model with a representative agent, the aggregate dividend is equal to the aggregate consumption; thus, the wealth will be the GDP of the

\footnotetext{
${ }^{8}$ Lettau and Ludvigson (2001) find that an observable version of the consumption-wealth ratio: a cointegration residual between $\log$ consumption $c, \log$ asset (nonhuman) wealth $a$, and log labor income $y$ (referred to as cay) has a striking forecasting power for excess returns on aggregate stock market index.

${ }^{9}$ Stock and Watson (1989) find that both the spread between six-month commercial paper and sixmonth Treasury bill rates, and the spread between ten and one-year Treasury bond rates outperform nearly every other variable as a forecaster of the business cycle.

${ }^{10} \mathrm{http}: / /$ faculty.haas.berkeley.edu/lettau/data.html
} 
whole country. The GDP and aggregate consumption of non-durables and services data are provided by U.S. Bureau of Economic Analysis. As for $(P+D) / D$, we use the price and dividend of S\&P 500 index. In addition to these two measures, we adopt Duffee's (2005) stock market wealth over consumption ratio (ME/C) as a proxy for the wealthdividend ratio when estimating the conditional linear factor models. The data is from Duffee's web page. ${ }^{11}$

We choose the three-month Treasury bill rate as the risk-free interest rate, which is obtained from the Federal Reserve Bulletin. Quarterly data are used when we treat GDP/C ratio as the wealth-dividend ratio. Otherwise, we use the monthly data. ${ }^{12}$ The period is from April 1953 to June 2012.

\subsection{Estimation of the Euler Equation: Estimates of $\psi$}

By using the scaling factors and scaling returns methodology to capture the conditional information, we estimate the logarithmic counterpart of equation (6). Panel A in Table 1 presents the estimates based on the four portfolios sorted by size, i.e. first, second, fifth and tenth deciles. The estimates for the intertemporal substitution parameter $\psi$ are highly significant, and its point estimate is around 1.2 under all three instrumental variable sets when GDP/C is used as the wealth-dividend ratio $K$, while the point estimate is around 1.1 when $(P+D) / D$ is used as $K$. The $J_{T}$ tests of overidentifying restrictions do not reject the model for all specifications.

\section{[Insert Table 1 about here.]}

As a robustness check, we rerun the above GMM estimation using other three alternative sets of portfolios: (a) six portfolios sorted by size and book-to-market equity, (b) six portfolios sorted by size and momentum, and (c) ten portfolios sorted by industry.

\footnotetext{
${ }^{11}$ http://www.econ.jhu.edu/people/Duffee/. Since the monthly data provided by Duffee is from January 1959 to May 2002, when we use ME/C as the proxy for wealth-dividend ratio, the testing period is restricted to this sample period.

${ }^{12}$ cay data is provided quarterly. We suppose it changes equally in each month within a quarter. By using the interpolation method, we span the quarterly data to monthly.
} 
The estimation results using six portfolios sorted by size and book-to-market equity are reported in Panel B. The EIS parameter $\psi$ is statistically significant for all specifications, and the overidentifying restrictions do not reject the model at the $5 \%$ level except when we use the default premium as instrument in the GDP/C measure. Panel $\mathrm{C}$ reports the estimation results based on six portfolios sorted by size and momentum. Again, the EIS parameter $\psi$ is statistically significant and its point estimate is about 1.1 in all cases. Also, the $J_{T}$ tests do not reject the shadow CAPM. Panel D reports the estimation results based on ten portfolios sorted by industry. EIS is statistically significant and its point estimate is around 1.1-1.2. However, the $J_{T}$ tests reject the model except for the case in which GDP-consumption ratio is taken as the proxy for the wealth-dividend ratio $K$.

To summarize, the $J_{T}$ tests do not reject the shadow CAPM for most of the cases. The key parameter elasticity of intertemporal substitution $(\psi)$ is statistically significant and its point estimate is consistently around 1.1-1.2. The question is how does this result compare with the existing studies. The value of the elasticity of intertemporal substitution has been the subject of a long-lasting debate in the literature. Mehra and Prescott (1985) restrict the risk aversion and intertemporal substitution parameter $\gamma$ to be in $0<\gamma \leq 10$, mainly because they interpret that $\gamma$ measures the consumption substitution, and the value in this range fits the observed life cycle savings pattern. Hall (1988) and Campbell (1999) estimate $\psi$ to be well below unity. However, Hansen and Singleton (1982) estimate $\psi$ to be well in excess of 1.5. Attanasio and Weber (1989) document an EIS greater one in the United Kingdom. Vissing-Jorgensen (2002) and Guvenen (2006) also have argued that $\psi$ is well over unity. Bansal and Yaron (2004) argue that the results of $\psi$ less than unity are based on a model without fluctuating economic uncertainty. They show that ignoring this time-varying economic effects would lead to a downward bias in the estimation of $\psi$. Thus, our result that $\psi$ is greater than unity is consistent with Attanasio and Weber (1989), Vissing-Jorgensen (2002), Bansal and Yaron (2004), and Guvenen (2006). 


\subsection{Unconditional Linear Factor Models}

As it is clear from equation (5), the shadow CAPM reduces to the CAPM when the shadow price $\Lambda_{t}$ is deterministic. In other words, if $\Lambda_{t}$ is random, the shadow CAPM would outperform the CAPM. To see this, we compare the estimations of the unconditional linear factor specifications of the shadow CAPM and CAPM. Then, we compare the shadow CAPM with several representative conditional and unconditional models in the literature.

\subsubsection{The shadow CAPM versus the CAPM}

We use the 25 Fama-French portfolios sorted by size and book-to-market equity to estimate the unconditional linear factor models. Column 2 of Table 2 reports estimates of factor risk prices for the CAPM. The last two columns in Table 2 are the estimates for the shadow CAPM, expressed as equation (8). All estimations are using the standard two-step GMM approach. Only a constant is used as the instrument. In the shadow CAPM results, the risk price for the wealth-dividend ratio $K_{t}$ is significantly negative, which implies that the wealth-dividend beta, i.e. $\operatorname{Cov}\left(k_{t}, R_{t}^{j}-R_{t}^{f}\right) / \operatorname{Var}\left(k_{t}\right)$, has a negative impact on the asset $j$ 's expected excess return. It is worthwhile to note that since the point estimate of $\psi$ is greater than unity, the wealth-dividend ratio $K_{t}$ will have the same sign as the shadow price $\Lambda_{t}$. This is consistent with the prediction of equation (5) that the excess returns and covariance of stock returns with wealth-dividend ratio are negatively related. The risk prices for market return are positive but with less significance level under the payoff-dividend ratio measure.

[Insert Table 2 about here.]

As for the estimation results for the CAPM, the risk price on the market return is statistically significant and positive. The mean absolute pricing error (MAE) from the first stage is $0.20 \%$ per month. Also, we report the adj- $R^{2}$, which is defined as one minus the mean square pricing error to the variance of average portfolio returns by following 
Campbell and Vuoleenaho (2004). This definition allows for negative adj- $R^{2}$ for poorly fitting models, which implies that the models have less explanatory power than simply predicting constant average returns across portfolios. The adj- $R^{2}$ for the CAPM is $-44 \%$, while it is positive for the shadow CAPM. The mean absolute pricing error and adj- $R^{2}$ indicate that the shadow CAPM performs much better than the CAPM.

As noted above, the shadow CAPM reduces to the CAPM when the asset returns are i.i.d or the shadow price $\Lambda_{t}$ is deterministic. However, the shadow price $\Lambda_{t}$ is a function of the wealth-dividend ratio $K_{t}$, which is closely related to the price-earnings ratio (or the price-dividend ratio). It is well-known that the $\mathrm{P} / \mathrm{E}$ (or $\mathrm{P} / \mathrm{D})$ process is stochastic (for instance, Shiller 2005), so does the shadow price $\Lambda_{t}$. Thus, it is not surprising that the shadow CAPM outperforms the CAPM, since the shadow CAPM can capture the time-varying effect, unlike the CAPM.

One may argue that it is more reasonable to compare the conditional CAPM with the shadow CAPM, since the conditional CAPM could capture the time-varying property in asset returns. We examine the Lettau and Ludvigson (2001)'s conditional CAPM. In their model, they propose cay and the interaction term of cay with the market factor as two additional factors to capture the time-varying effect. The estimation results for the conditional CAPM are reported in the second column of Table 3. Comparing with the unconditional CAPM results in Table 2, conditional CAPM performs much better. It has a higher adj- $R^{2}$ and lower MAE. However, The adj- $R^{2}$ is still negative and the $J$-test does not support the conditional CAPM. These findings lead us to conclude that the shadow CAPM performs better than both the conditional and unconditional CAPM.

\subsubsection{Comparisons with other models}

In what follows, we compare the unconditional linear factor version of the shadow CAPM with several representative models in the literature: Fama and French (1993) three-factor model, the consumption CAPM with power utility (CCAPM), Epstein-Zin's (1991) model with recursive utility. The details of these models are provided in Appendix C. The test 
portfolios are based on the 25 Fama-French portfolios sorted by size and book-to-market equity.

The estimates of factor risk prices for these three models are also reported in Table 2. We use a constant as the instrument for these models as well. The Fama-French three-factor model is well-known for its ability in capturing stock returns, and indeed the results here do not contradict with the claim. The mean absolute pricing error (MAE) is $0.12 \%$, and the adj- $R^{2}$ is $42 \%$. The risk price for HML (High Minus Low) is significantly positive, while the risk price for SMB (Small Minus Big) is insignificant. The performance of the Fama-French three-factor model is better than the shadow CAPM in terms of the MAE and $\operatorname{adj}-R^{2}$. The $J$-test, however, rejects the model.

The risk price for the consumption growth is significantly positive in the CCAPM. Its point estimate is rather large (at 234), which is a consequence of the very low volatility of the consumption growth rate. The mean absolute pricing error is $0.22 \%$ and the adj$R^{2}$ is $-18 \%$. The overidentifying test strongly rejects the model. For the Epstein-Zin recursive utility model, both the risk prices for consumption growth and market return are significantly positive. The MAE is $0.19 \%$ per month and the adj- $R^{2}$ is $-30 \%{ }^{13}$ These results illustrate that the shadow CAPM outperforms the Epstein-Zin model and CCAPM. It is not surprising that the shadow CAPM performs much better than CCAPM, since shadow CAPM assumes the recursive utility which breaks the tight link between the elasticity of intertemporal substitution and risk aversion. Moreover, our results show that the shadow CAPM outperforms the Epstein-Zin model. The difference between the shadow CAPM and the Epstein-Zin model relies on the assumption about the form of the certainty equivalent. Thus, we may conclude that the more general assumption of w-MPS risk aversion in the certainty equivalent is a better way to capture people's behavior than strictly assuming the expected utility in the certainty equivalent.

\footnotetext{
${ }^{13}$ We need to treat with caution when interpret the value of MAE here. MAE is the mean absolute pricing error for the 25 portfolios. It is suffered easily by the extreme values here. The MAE for the shadow CAPM is larger than that of Fama-French model. The reason is because the uncondtional shadow CAPM cannot explain the two bottom portfolios in Figure 1 and the pricing errors have a big impact in calculating MAE.
} 
Furthermore, we estimate the conditional models for CCAPM, Epstein-Zin model and Jagannathan and Wang (1996) human capital CAPM ${ }^{14}$. Table 3 present the estimation results for these conditional models. The conditional CCAPM performs better than the unconditional CCAPM, with a smaller MAE and relatively higher $\operatorname{adj}-R^{2}$. But the adj- $R^{2}$ is still negative and $J$-statistic does not support the model. The results for Epstein-Zin model become even worse under the conditional setting. One possible reason is that here we use the cay as the only variable to scale factors. A better way would be to use several instrumental variables and scale returns as well. The human capital CAPM does not perform well. The MAE is $0.21 \%$ per month, the adj- $R^{2}$ has a negative value of $-35 \%$ and the $J$-statistic does not support the model. Above all, all of these conditional models perform worse than the unconditional shadow CAPM under the MAE and adj- $R^{2}$.

[Insert Figure 1 about here.]

[Insert Figure 2 about here.]

In Figures 1 and 2, we plot the excess return predicted by each unconditional and conditional model based on the first-stage estimates and the realized average excess return for the 25 Fama-French portfolios so that we can visually compare the performance of shadow CAPM with that of other models. The vertical distance to the 45-degree line represents the pricing error of the portfolio. In terms of the pricing errors, the unconditional shadow CAPM (Panels e and $\mathrm{f}$ in Figure 1) outperforms the CAPM (Panel a), the CCAPM (Panel c), and the Epstein-Zin model (Panel d) in Figure 1. It is only outperformed by Fama-French model (Panel b in Figure 1). The shadow CAPM outperforms all conditional models in Figure 2. The two data points at the bottom of each panel are S1V1 and S2V1, which correspond to the two smallest size portfolios in the lowest bookto-market equity quintile. This indicates that all these models, including Fama-French, have some difficulties when explaining the performance of these two portfolios.

\footnotetext{
${ }^{14}$ The labor income data are provided by U.S. Bureau of Economic Analysis. We follow the same methodology as Jagannathan and Wang (1996) when calculating the labor income variable.
} 


\subsubsection{Cross-sectional variations in the Fama-French portfolios}

To enhance the better understanding of the success of the shadow CAPM, here we tackle the original version of the shadow CAPM (equation 5). Table 4 reports $\alpha_{\Lambda}^{j}$ and $\gamma_{\Lambda}^{j}$ for the 25 Fama-French portfolios by using the estimate of the elasticity of intertemporal substitution $(\psi)$ from Table 1. To find out the conditional $\alpha_{\Lambda}^{j}$ and $\gamma_{\Lambda}^{j}$ for the 25 portfolios, we need to scale factors and returns by instruments, which will lead to an explosion of moment conditions. Thus, we report the unconditional $\alpha_{\Lambda}^{j}$ and $\gamma_{\Lambda}^{j}$ here. The estimated values for EIS are quite close under different instrumental variable sets and different test portfolios in Table 1. We take the average value of EIS among all the instrumental variable sets and portfolios for each measure of the wealth-dividend ratio.

Panel A in Table 4 reports the average excess returns for the 25 Fama-French portfolios sorted by size and book-to-market equity (BE/ME). It confirms the well-known size and value premia. Reading down the columns, average excess returns decrease in size for a given $\mathrm{BE} / \mathrm{ME}$ quintile. The only exception is for the lowest $\mathrm{BE} / \mathrm{ME}$ quintile, whose returns roughly increase in size. Reading across the rows, average excess returns increase in $\mathrm{BE} / \mathrm{ME}$ for a given size quintile.

Panel B in Table 4 reports $\alpha_{\Lambda}^{j}$ in the shadow CAPM (equation 5 ). $\alpha_{\Lambda}^{j}$ is similar to the definition of beta in CAPM, with the shadow returns in place of the returns. Since the average estimated values for $\psi$ are quite close between the two wealth-dividend ratio measures, we only report $\alpha_{\Lambda}^{j}$ when $K=(P+D) / D$. Reading down the columns of the panel, $\alpha_{\Lambda}^{j}$ decreases in size for a given BE/ME quintile. This pattern is consistent with the size premium. However, reading across the rows, the growth stocks have a higher $\alpha_{\Lambda}^{j}$ than the value stocks for a given size quintile, which is not consistent with the value premium. This result sheds lights on why the CAPM fails to explain the asset returns.

Panel $\mathrm{C}$ reports $\gamma_{\Lambda}^{j}$ in equation (5) given $(P+D) / D$ as the wealth-dividend measure. Reading down the columns of the panel, $\gamma_{\Lambda}^{j}$ decreases in size for a given BE/ME quintile. The only exception is for the lowest BE/ME quintile, while this exception is just consistent with the average returns in that quintile. We can also get the answer for the two bottom 
points in Figure 1: $\gamma_{\Lambda}^{j}$ is relatively low for S1V1 and S2V1 portfolios, but $\alpha_{\Lambda}^{j}$ is extremely high for them, thus the predicted returns are much larger than the realized returns. Reading across the rows, $\gamma_{\Lambda}^{j}$ increases in $\mathrm{BE} / \mathrm{ME}$ for a given size quintile.

Panel D reports $\gamma_{\Lambda}^{j}$ given the GDP/C as the wealth-dividend measure. The results are similar as those in Panel $\mathrm{C}$. The variations in size for a given BE/ME quintile and the variations in $\mathrm{BE} / \mathrm{ME}$ for a given size quintile are consistent with the average returns.

Above all, $\gamma_{\Lambda}^{j}$ contributes to the success of the shadow CAPM in explaining the asset returns cross-sectionally. $\alpha_{\Lambda}^{j}$ accounts for the variations in average return across size.

\subsection{Time Variation in Expected Returns}

\subsubsection{Unconditional covariance}

Before estimating the conditional linear factor model, we re-run the unconditional linear factor model (8) of the shadow CAPM with the instruments. The testing portfolio returns are excess returns on the four portfolios sorted by size, i.e. the first, second, fifth, and tenth deciles. By following Duffee (2005), we use the ratio of stock market wealth over consumption $(\mathrm{ME} / \mathrm{C})$ as a robustness check for the wealth-dividend ratio $K_{t}$ in addition to $(P+D) / D$ and GDP/C. Table 5 reports the estimation results when the instrumental variables are the term premium, the dividend-price ratio and a constant. ${ }^{15}$ All the risk prices are statistically significant under these three different wealth-dividend ratio measures. Moreover, all the coefficients for the covariance with the wealth-dividend ratio are negative, which is consistent with the prediction of the shadow CAPM. The $J$-statistics for overidentifying test do not reject the shadow CAPM under all specifications.

[Insert Table 5 about here.]

\footnotetext{
${ }^{15}$ The results are quite similar when cay or default premium sets are used as instrumental variables. The results are available upon request.
} 


\subsubsection{Conditional linear factor model}

We use the same four portfolios' excess returns to estimate equations (10) and (11). The instrumental variables are $T R M$, dividend-price ratio and a constant. ${ }^{16}$ We estimate the risk prices $b_{1}$ and $b_{2}$ together with the conditional covariances. Here we use four portfolios, two factors and three instruments. Thus, there are 36 moment functions in total. 12 moment functions come from the conditional mean estimation, and 24 functions come from the conditional covariance estimation. The model is therefore overidentified by $N I-L=10$ degrees.

[Insert Table 6 about here.]

[Insert Table 7 about here.]

Tables 6 and 7 present the estimation results of the conditional linear factor version of the shadow CAPM. The estimates of the risk prices are reported in Table 6: The market risk prices are significantly positive, and the wealth-dividend ratio risk prices are significantly negative under all the different wealth-dividend ratio measures. Panel A of Table 7 reports the estimates of equation (10), i.e. the regression model of the conditional mean of returns. The term premium (TRM) is significant and positive for all four portfolios. The dividend-price ratio is positive at least at the $10 \%$ level for all four portfolios. Panels B to D report estimates of equation (11) the regression model of the conditional covariance of returns with different measures of wealth-dividend ratio. All the coefficients are negative and most of them are significant at the $5 \%$ level. The statistical significance means that the term premium and the dividend-price ratio predict the product of the innovation to returns with the wealth-dividend ratio. The negative coefficients indicate that when term premium and dividend-price ratio are high, the conditional covariance of stock returns with the wealth-dividend ratio is low. In other words, the conditional covariance of stock returns with wealth-dividend ratio is procyclical. With the negative risk price of the wealth-dividend ratio, the conditional covariance explains the countercyclical property of the excess returns.

\footnotetext{
${ }^{16}$ The results for instrument sets of $c a y$ and $D E F$ are similar. The results are available upon request.
} 
Figure 3 is a time series plot of the expected excess return on the 5th size portfolio, implied by the estimates in Table 6 and 7. Each panel in the figure is for each wealthdividend ratio measure. The dark line represents the equity premium, and the light line represents the part due to wealth-dividend ratio $b_{2} \operatorname{Cov}_{t}\left(k_{t+1}, R_{t+1}^{j}-R_{t+1}^{f}\right)$. The difference is the premium due to the market risk. This figure reveals two interesting facts. First, the equity premium and the the premium contributed by wealth-dividend ratio have a similar moving pattern under all three measures. This implies that most of the time-variation in the equity premium are driven by the variation in wealth-dividend ratio. This explains why the CAPM fails to explain the time-variation in expected returns because it misses an important component of the cyclical variation in the equity premium. Second, the equity premium is strongly countercyclical, high at business cycle troughs and low at business cycle peaks. The plots for the other three portfolios are quite similar, thus are omitted.

[Insert Figure 3 about here.]

Another very important result is that the shadow CAPM can help explain the size anomaly. Panels B to D in Table 7 show that a smaller portfolio has a higher risk measured by the covariance with the wealth-dividend ratio than that of a larger portfolio. The conditional covariance of the smallest size portfolio with the wealth-dividend ratio is more procyclical. This procyclical property explains its high average return.

To further verify our finding, we add the SMB factor of the Fama-French three factor model to the shadow CAPM. If the shadow CAPM can capture the size effect, the SMB factor should have no power to explain asset returns. In our unreported estimation results, we find that the risk price for the SMB factor is insignificant for all three specifications but the risk prices for market and wealth-dividend ratio are still significant; thus, the size effect is sufficiently captured by the shadow CAPM. 


\section{Conclusion}

The shadow CAPM of Ma (2011a) assumes the weak form mean-preserving spread risk aversion in the certainty equivalent of the Epstein and Zin (1989) recursive utility. The w-MPS risk aversion in CE is a more general setup than the expected utility functional CE in the Epstein-Zin model. The shadow price along with the market portfolio return are the two factors that explain the equity premium in shadow CAPM instead of consumption growth with market return in Epstein-Zin model. In the shadow CAPM, the unobservable shadow price can be expressed as the function of wealth-dividend ratio with the EIS parameter $\psi$. We have estimated the Euler equation of the shadow CAPM considering the wealth-dividend ratio as GDP-consumption ratio $(\mathrm{GDP} / \mathrm{C})$ and payoff-dividend ratio $(P+D) / D$, respectively. The EIS parameter $\psi$ is statistically significant and its point estimate is greater than unity.

Moreover, we estimated the unconditional linear factor model of the shadow CAPM by using the 25 Fama and French portfolios, and compared its performance with the CAPM, CCAPM, Epstein-Zin model, Jagannathan-Wang human capital model and Fama and French (1993) three-factor model. The shadow CAPM outperformed all these models except the Fama-French three-factor model.

Furthermore, we estimated the conditional linear factor model of the shadow CAPM. The results show that it can explain both the cross-section of expected returns of stocks and the time variation in the equity premium. The conditional covariances of the returns with wealth-dividend ratio are procyclical, and the risk price for the wealth-dividend ratio is negative. This explains the countercyclical expected returns. We also find that the smaller size portfolio has a higher risk measured by the conditional covariance with the wealth-dividend ratio. This finding can help explain the size anomaly. These results imply that the shadow CAPM is a model that has a theoretical foundation and is helpful in explaining the stock market phenomena. Above all, we may conclude that the recursive utility with w-MPS risk aversion could be a good way to model representative agent's behavior in the real economy. 


\section{Appendix A. Derivation of the Shadow CAPM}

Here, for reader's convenience, we provide an mathematical appendix for the derivation of the shadow CAPM.

We assume stationary Markov information structure and Lucas exchange economy with recursive utility function prescribed in Section 2. The representative agent's preference over the consumption stream $\mathbf{c}=\left\{c_{t}\right\}_{t \in(0,1, \ldots)}$ is summarized by Epstein and Zin's (1989) recursive utility of the form

$$
U_{t}(\mathbf{c})=H\left(c_{t}, \mathrm{CE}\left[U_{t+1}(\mathbf{c}) \mid \mathcal{F}_{t}\right]\right)
$$

where $H(c, v)$ is called the utility aggregator, and $\mathrm{CE}\left[\cdot \mid \mathcal{F}_{t}\right]$ is the certainty equivalent that ranks future utility $U_{t+1}(\mathbf{c})$ conditional on the current information $\mathcal{F}_{t}$.

Further, we consider the recursive utility generator with a constant elasticity of intertemporal substitution

$$
H(c, v)=\left(c^{\rho}+\beta v^{\rho}\right)^{1 / \rho}, \quad \rho<1 \text { and } \rho \neq 0,
$$

where parameter $\rho$ measures the degree of intertemporal substitution with elasticity of intertemporal substitution (EIS) given by $\psi=1 /(1-\rho)$, and a homothetic certainty equivalent

$$
\mathrm{CE}\left[\eta x \mid \mathcal{F}_{t}\right]=\eta \mathrm{CE}\left[x \mid \mathcal{F}_{t}\right], \quad \forall \eta, t
$$

The certainty equivalent is assumed to display weak form Mean-Preserving-Spread (wMPS) risk aversion in the sense that for every $X$,

$$
\mathrm{CE}[X] \geq \mathrm{CE}[X+\varepsilon], \quad \text { with } \mathbb{E}[\varepsilon]=0 \text { and } \operatorname{Cov}(X, \varepsilon)=0 \text {. }
$$

The w-MPS risk aversion constitutes the key behavioral assumption for the shadow CAPM. 
There are a total number of $J$ risky securities available for trading. $\theta^{j}$ stands for the proportion invested in security $j$, with $\theta^{0}=1-\sum_{j \in J} \theta^{j}$ being the proportion invested in the risk free saving account. The portfolio return under $\theta$ is thus given by $R_{t+1}[\theta]=$ $R_{t}^{f}+\sum_{j \in J} \theta^{j}\left(R_{t+1}^{j}-R_{t}^{f}\right)$.

Assume that the market admits no arbitrage opportunities so that the optimal portfolio exists. Following the standard dynamic programming argument, the value function for the optimal choice problem is to take the form $V(x, W)=\Lambda(x) W$, where $\Lambda(x)$ is the "shadow price" at state $x$. The Bellman equation for investor's portfolio choice problem becomes

$$
\Lambda_{t} W_{t}=\max _{c} H\left(c, \max _{\theta} \mathrm{CE}_{t}\left(\Lambda_{t+1} W_{t+1}\right)\right)
$$

in which $W_{t+1}=\left(W_{t}-c_{t}\right) R_{t+1}[\theta]$.

By assumption, $\mathrm{CE}[\cdot]$ is homothetic. So, we may write

$$
\mathrm{CE}_{t}\left(\Lambda_{t+1} W_{t+1}\right)=\left(W_{t}-c_{t}\right) \mathrm{CE}_{t}\left(\Lambda_{t+1} R_{t+1}[\theta]\right)
$$

The optimal portfolio $\theta_{t}^{*}$ must be invariant to $W_{t}$ and $c_{t}$, and the optimal portfolio choice problem reduces to

$$
\max _{\theta} \mathrm{CE}_{t}\left(\Lambda_{t+1} R_{t+1}[\theta]\right)
$$

Denote $\widehat{R}_{t+1}[\theta]=\frac{\Lambda_{t+1}}{\mathbb{E}_{t}\left[\Lambda_{t+1}\right]} R_{t+1}[\theta]$ with $\widehat{R}_{t+1}[\emptyset]=\frac{\Lambda_{t+1}}{\mathbb{E}_{t}\left[\Lambda_{t+1}\right]} R_{t}^{f}$. We interpret $\widehat{R}_{t+1}$ as shadow returns. The optimal portfolio choice problem can be reformulated as

$$
\max _{\theta} \mathrm{CE}_{t}\left(\widehat{R}_{t+1}[\theta]\right)
$$

To further explore qualitative properties of the optimal portfolio, we need to introduce the following Markowitz shadow mean-variance efficient frontier, or simply, the shadow frontier.

$$
\widehat{\mathcal{I}}_{t}=\left\{(\mu, \sigma) \in \mathbb{R} \times \mathbb{R}_{+}: \sigma=\min _{\theta}\left\{\sigma_{t}\left[\widehat{R}_{t+1}[\theta]\right]: \mathbb{E}_{t}\left[\widehat{R}_{t+1}[\theta]\right]=\mu\right\}\right\}
$$


which corresponds to Markowitz mean-variance efficient frontier obtained from shadow returns $\widehat{R}_{t+1}$.

The shadow frontier $\widehat{\mathcal{I}}_{t}$ inherits all the mathematical properties of the standard Markowitz mean-variance efficient frontier. Particularly, we have:

Lemma 1 (1). If $\theta_{0}$ is on $\widehat{\mathcal{I}}_{t}$, then for all $\theta$ that achieves the same shadow expected return, $\widehat{R}_{t+1}[\theta]$ must be expressed as a w-MPS of $\widehat{R}_{t+1}\left[\theta_{0}\right]$; that is, there exists $\varepsilon^{\theta}$ such that $\widehat{R}_{t+1}[\theta]=\widehat{R}_{t+1}\left[\theta_{0}\right]+\varepsilon_{t+1}^{\theta}, \mathbb{E}_{t}\left[\varepsilon_{t+1}^{\theta}\right]=0$ and $\operatorname{Cov}_{t}\left(\widehat{R}_{t+1}\left[\theta_{0}\right], \varepsilon_{t+1}^{\theta}\right)=0$.

(2) Convex combinations of shadow efficient portfolios are shadow efficient; and any particular shadow efficient portfolio can be expressed as an extended convex combination of two arbitrary distinct shadow efficient portfolios.

(3) For all $\theta$, it holds true that

$$
\mathbb{E}_{t}\left[\widehat{R}_{t+1}[\theta]\right]-R_{t}^{f}=\widehat{\beta}_{t}^{\theta}\left[\theta_{m}\right]\left(\mathbb{E}_{t}\left[\widehat{R}_{t+1}\left[\theta_{m}\right]\right]-R_{t}^{f}\right)
$$

in which $\widehat{\beta}_{t}^{\theta}\left[\theta_{m}\right]=\frac{\operatorname{Cov}_{t}\left(\widehat{R}_{t+1}[\theta], \widehat{R}_{t+1}\left[\theta_{m}\right]\right)}{\operatorname{Var}_{t}\left(\widehat{R}_{t+1}\left[\theta_{m}\right]\right)}$ and $\theta_{m}$ is the tangent portfolio (on $\widehat{\mathcal{I}}_{t}$ ) at which the tangent line intersects the $\mu$ axis at $R_{t}^{f}$.

(4) Let $\theta_{r}$ be the shadow efficient portfolio at $\mu=R_{t}^{f}$. Then, we have $\widehat{\beta}_{t}^{\theta_{r}}\left[\theta_{m}\right]=$ $\widehat{\beta}_{t}^{\emptyset}\left[\theta_{m}\right]=0$; and, for all $\theta$, the following risk decomposition holds

$$
\widehat{R}_{t+1}[\theta]=\widehat{R}_{t+1}\left[\theta_{r}\right]+\widehat{\beta}_{t}^{\theta}\left[\theta_{m}\right]\left(\widehat{R}_{t+1}\left[\theta_{m}\right]-\widehat{R}_{t+1}\left[\theta_{r}\right]\right)+\varepsilon_{t+1}^{\theta}
$$

in which $\varepsilon_{t+1}^{\theta}$ has zero mean, and is uncorrelated with $\widehat{R}_{t+1}\left[\theta_{m}\right]$ and $\widehat{R}_{t+1}\left[\theta_{r}\right]$.

Proof. The proofs are standard, and are thus omitted.

The first statement in Lemma 1 is analogue to Boyle and Ma (2013, Proposition 1) in static setting. The second statement of Lemma 1 is analogous to Black's Two-Fund Separation Theorem. To verify the validity of the statement, we assume that the following two purely technical conditions hold: 
- The shadow variance and covariance matrix $\left(\Sigma_{\Lambda}\right)$ is non-singular;

- non-degeneracy: The expected shadow return vector $\mu_{\Lambda}$ is not proportional to the $(J+1)$-dimensional unit vector $\overline{1}$; that is, there exist two securities with different expected shadow returns.

In fact, under these conditions we can readily compute the shadow efficient portfolio at arbitrarily $\mu$ by solving the standard quadratic optimization under constraints. We obtain

$$
\theta_{0}=\Sigma_{\Lambda}^{-1}\left[\mu_{\Lambda}, \overline{1}\right]\left(\left[\mu_{\Lambda}, \overline{1}\right]^{\top} \Sigma_{\Lambda}^{-1}\left[\mu_{\Lambda}, \overline{1}\right]\right)^{-1}\left[\begin{array}{c}
\mu \\
1
\end{array}\right]
$$

From this analytic expression, we can readily check the validity of two-fund separation as asserted in Lemma 1-(2).

The third and the fourth statements of Lemma 1 correspond respectively to the well known "linear- $\beta$ model" and "risk decomposition".

By assumption, CE[·] displays w-MPS risk aversion. So, as a direct corollary to Lemma 1-(1), we can assert that

Proposition 1 The optimal portfolio $\theta_{t}^{*}$, if exists, must be shadow efficient.

In equilibrium, the representative investor optimally holds the market portfolio $\theta^{m}$. So, as a corollary to Proposition 1 , we conclude that $\theta^{m}$ must belongs to the shadow efficient frontier. Moreover, we can show the validity of the following shadow CAPM as an equilibrium asset pricing model.

Proposition 2 In equilibrium, it holds true that

$$
\mathbb{E}_{t}\left[\widehat{R}_{t+1}[\theta]\right]-R_{t}^{f}=\widehat{\alpha}_{t}^{\theta}\left(\mathbb{E}_{t}\left[\widehat{R}_{t+1}^{m}\right]-R_{t}^{f}\right)
$$

in which $\widehat{R}_{t+1}^{m}=\frac{\Lambda_{t+1}}{\mathbb{E}_{t}\left[\Lambda_{t+1}\right]} R_{t+1}^{m}$ is the shadow return for the market portfolio, $\widehat{\alpha}_{t}^{\theta}=\frac{\widehat{\beta}_{t}^{\theta}-\widehat{\beta}_{t}^{\emptyset}}{1-\widehat{\beta}_{t}^{\emptyset}}$, $\widehat{\beta}_{t}^{\theta}=\frac{\operatorname{Cov}_{t}\left(\widehat{R}_{t+1}[\theta], \widehat{R}_{t+1}^{m}\right)}{\operatorname{Var}_{t}\left(\widehat{R}_{t+1}^{m}\right)}$ and $\widehat{\beta}_{t}^{\emptyset}=\frac{\operatorname{Cov}_{t}\left(\widehat{R}_{t+1}[\emptyset], \widehat{R}_{t+1}^{m}\right)}{\operatorname{Var}_{t}\left(\widehat{R}_{t+1}^{m}\right)}$. 
Proof. By Lemma 1-(2), the market portfolio $\theta^{m}$ must be expressed as a convex combination of $\theta_{m}$ and $\theta_{r}$. The shadow return $\widehat{R}_{t+1}^{m}$ for the market portfolio can be thus expressed as

$$
\widehat{R}_{t+1}^{m}=\widehat{\beta}_{t}^{\theta^{m}}\left[\theta_{m}\right] \widehat{R}_{t+1}\left[\theta_{m}\right]+\left(1-\widehat{\beta}_{t}^{\theta^{m}}\left[\theta_{m}\right]\right) \widehat{R}_{t+1}\left[\theta_{r}\right]
$$

Equation A.8 on risk decomposition can be thus re-written as

$$
\widehat{R}_{t+1}[\theta]=\widehat{R}_{t+1}\left[\theta_{r}\right]+\widehat{\alpha}_{t}^{\theta}\left(\widehat{R}_{t+1}^{m}-\widehat{R}_{t+1}\left[\theta_{r}\right]\right)+\varepsilon_{t+1}^{\theta}
$$

in which $\widehat{\alpha}_{t}^{\theta}=\widehat{\beta}_{t}^{\theta}\left[\theta_{m}\right] / \widehat{\beta}_{t}^{\theta^{m}}\left[\theta_{m}\right]$, and $\varepsilon_{t+1}^{\theta}$ is uncorrelated with $\widehat{R}_{t+1}^{m}$ and $\widehat{R}_{t+1}\left[\theta_{r}\right]$.

From equation (A.10), we obtain the following alternative expression for the coefficient $\widehat{\alpha}_{t}^{\theta}$ that is given by

$$
\widehat{\alpha}_{t}^{\theta}=\frac{\operatorname{Cov}_{t}\left(\widehat{R}_{t+1}[\theta]-\widehat{R}_{t+1}\left[\theta_{r}\right], \widehat{R}_{t+1}^{m}\right)}{\operatorname{Cov}_{t}\left(\widehat{R}_{t+1}^{m}-\widehat{R}_{t+1}\left[\theta_{r}\right], \widehat{R}_{t+1}^{m}\right)}=\frac{\widehat{\beta}_{t}^{\theta}-\widehat{\beta}_{t}^{\theta_{r}}}{1-\widehat{\beta}_{t}^{\theta_{r}}} .
$$

In particular, for $\theta=\emptyset$, with $\widehat{\alpha}_{t}^{\emptyset}=\widehat{\beta}_{t}^{\emptyset}\left[\theta_{m}\right] / \widehat{\beta}_{t}^{\theta^{m}}\left[\theta_{m}\right]=0$, we obtain $\widehat{\beta}_{t}^{\theta_{r}}=\widehat{\beta}_{t}^{\emptyset}$. This yields

$$
\widehat{\alpha}_{t}^{\theta}=\frac{\widehat{\beta}_{t}^{\theta}-\widehat{\beta}_{t}^{\emptyset}}{1-\widehat{\beta}_{t}^{\emptyset}} .
$$

Taking expectations on both sides of equation (A.10), we obtain shadow-CAPM (i.e., Eq. A.9) as an equilibrium asset pricing model.

It remains to characterize the equilibrium shadow price $\Lambda_{t}$. Let $P_{t}$ be the equilibrium price (at $t$ ) for the market portfolio. Recalling that, for Lucas (1978) exchange economy of representative agent, at equilibrium, the representative investor optimally holds the market portfolio and consume the aggregate dividend. The equilibrium wealth is thus given by $W_{t}=D_{t}+P_{t}$.

Let $K_{t}=P_{t} / D_{t}+1$. We can readily prove the following characterization theorem for the shadow price $\Lambda_{t}$ : 
Proposition 3 In equilibrium, the shadow price is given by $\Lambda_{t}=K_{t}^{(1-\rho) / \rho}$.

Proof. Since, in equilibrium, the representative investor optimally holds the market portfolio and consume the aggregate dividend, the Bellman equation must holds with

$$
\Lambda_{t} W_{t}=\max _{c t} H\left(c_{t},\left(W_{t}-c_{t}\right) C E_{t}\left[\Lambda_{t+1} R_{t+1}^{m}\right]\right)
$$

and the unique solution is achieved at $c_{t}=D_{t}$.

From the FOC:

$$
H_{c}-H_{v} C E_{t}\left[\Lambda_{t+1} R_{t+1}^{m}\right]=0
$$

we obtain

$$
\frac{W_{t}}{c_{t}}=1+\beta^{\frac{1}{1-\rho}} C E_{t}^{\frac{\rho}{1-\rho}}\left[\Lambda_{t+1} R_{t+1}^{m}\right]
$$

Applying the Envelop theorem to the Bellman equation (A.5), we obtain

$$
\Lambda_{t}=H_{v} C E_{t}\left[\Lambda_{t+1} R_{t+1}^{m}\right]=H_{c}
$$

or, explicitly,

$$
\Lambda_{t}^{\rho / 1-\rho}=1+\beta\left(\frac{W_{t}}{c_{t}}-1\right)^{\rho} C E_{t}^{\rho}\left[\Lambda_{t+1} R_{t+1}^{m}\right]
$$

Combining equations (A.11) and (A.12), we obtain

$$
\Lambda_{t}^{\rho / 1-\rho}=\frac{W_{t}}{c_{t}}=1+\frac{P_{t}}{D_{t}}=K_{t}
$$

The shadow CAPM as an equilibrium asset pricing model is thus obtained by combining Propositions 2 and 3 . 


\section{Appendix B. Derivation of the SDF formulation of the Shadow CAPM (Equation 6)}

To implement the GMM estimation of the Shadow CAPM, we need to express the equation

(4) in the stochastic discount factor model of asset prices. Denote $X_{t+1}^{j}$ the payoff of asset $j$ at time $t+1$, and $P_{t}^{j}$ the price of asset $j$ at time $t$. The equation (4) can be rewritten as

$$
\mathbb{E}_{t}\left[\frac{\Lambda_{t+1}}{\mathbb{E}_{t}\left[\Lambda_{t+1}\right]} \frac{X_{t+1}^{j}}{P_{t}^{j}}\right]=R_{f}+\frac{\operatorname{Cov}_{t}\left(\widehat{R}_{t+1}^{m}, \frac{\Lambda_{t+1}}{\mathbb{E}_{t}\left[\Lambda_{t+1}\right]} \frac{X_{t+1}^{j}}{P_{t}^{j}}-\widehat{R}_{t+1}^{f}\right)}{\operatorname{Cov}\left(\widehat{R}_{t+1}^{m}-\widehat{R}_{t+1}^{f}, \widehat{R}_{t+1}^{m}\right)}\left(\mathbb{E}_{t}\left[\widehat{R}_{t+1}^{m}\right]-R_{t}^{f}\right)
$$

Multiplying $\mathbb{E}_{t}\left[\Lambda_{t+1}\right] P_{t}^{j}$ at both sides and rearranging it, we obtain following expression for the equilibrium price:

$$
P_{t}^{j}=\mathbb{E}_{t}\left[\left(a_{t}+b_{t} \widehat{R}_{t+1}^{m}\right) \Lambda_{t+1} X_{t+1}^{j}\right]
$$

Equation (B.2) holds for any securities, particularly for the market portfolio and riskless asset. This yields two linear equations for the two model coefficients $\left(a_{t}\right.$ and $\left.b_{t}\right)$ :

$$
\begin{aligned}
1 & =\mathbb{E}_{t}\left[\left(a_{t}+b_{t} \widehat{R}_{t+1}^{m}\right) \Lambda_{t+1} R_{t}^{f}\right] \\
1 & =\mathbb{E}_{t}\left[\left(a_{t}+b_{t} \widehat{R}_{t+1}^{m}\right) \Lambda_{t+1} R_{t+1}^{m}\right]
\end{aligned}
$$

The solution is given by

$$
\left[\begin{array}{l}
a_{t} \\
b_{t}
\end{array}\right]=\left[\begin{array}{ll}
\mathbb{E}_{t}\left[\Lambda_{t+1}\right] & \mathbb{E}_{t}\left[\Lambda_{t+1} \widehat{R}_{t+1}^{m}\right] \\
\mathbb{E}_{t}\left[\widehat{R}_{t+1}^{m}\right] & \mathbb{E}_{t}\left[\left(\widehat{R}_{t+1}^{m}\right)^{2}\right]
\end{array}\right]^{-1}\left[\begin{array}{c}
1 / R_{t}^{f} \\
1 / \mathbb{E}_{t}\left[\Lambda_{t+1}\right]
\end{array}\right]
$$

Finally, we substitute the expression of shadow price $\Lambda_{t}=K_{t}^{(1-\rho) / \rho}$ with $A_{t}=a_{t}$ and $B_{t}=b_{t} / \mathbb{E}_{t}\left[\Lambda_{t+1}\right]$, we have equation (6). 


\section{Appendix C. Other Models}

\section{Conditional CAPM}

Generally speaking, the conditional counterpart of the linear factor model (equation 7) has the form

$$
\mathbb{E}_{t}\left[R_{t+1}^{j}-R_{t+1}^{f}\right]=\sum_{l}^{L} b_{l} \operatorname{Cov}_{t}\left(f_{l, t+1}, R_{t+1}^{j}-R_{t+1}^{f}\right)
$$

Lettau and Ludvigson (2001) propose cay as the instrument variable to scale factors in the conditional CAPM. They include cay, market excess return, the interaction term of cay with the market excess return as the factors. Based on equation (C.1), conditional CAPM has the form of

$$
\begin{aligned}
\mathbb{E}_{t}\left[R_{t+1}^{j}-R_{t+1}^{f}\right]= & b_{1} \operatorname{Cov}_{t}\left(\operatorname{cay}_{t}, R_{t+1}^{j}-R_{t+1}^{f}\right)+b_{2} \operatorname{Cov}_{t}\left(r_{t+1}^{m}-r_{t+1}^{f}, R_{t+1}^{j}-R_{t+1}^{f}(\mathrm{C} .2)\right. \\
& +b_{3} \operatorname{Cov}_{t}\left(\operatorname{cay}_{t}\left(r_{t+1}^{m}-r_{t+1}^{f}\right), R_{t+1}^{j}-R_{t+1}^{f}\right) .
\end{aligned}
$$

\section{Fama-French (1993) Model}

Fama and French (1993) proposed an influential three factor model. The three factors are excess return on the market portfolio, returns on the SMB (Small Minus Big) portfolio, and returns on the HML (High Minus Low) portfolio. Based on equation (7), Fama-French three factor model has the form of

$\mathbb{E}\left[R_{t}^{j}-R_{t}^{f}\right]=b_{1} \operatorname{Cov}\left(r_{t}^{m}-r_{t}^{f}, R_{t}^{j}-R_{t}^{f}\right)+b_{2} \operatorname{Cov}\left(S M B_{t}, R_{t}^{j}-R_{t}^{f}\right)+b_{3} \operatorname{Cov}\left(H M L_{t}, R_{t}^{j}-R_{t}^{f}\right)$.

Epstein-Zin (1991) Model and CCAPM 
Epstein and Zin (1989, 1991) and Weil (1989) propose a consumption-based model assuming the representative agent with recursive utility function. In their model, the stochastic discount factor is

$$
M_{t+1}=\beta\left(\frac{c_{t+1}}{c_{t}}\right)^{-\left(\frac{1-\gamma}{1-1 / \psi}\right) / \psi}\left(R_{t+1}^{m}\right)^{\left(\frac{1-\gamma}{1-1 / \psi}\right)-1}
$$

where $\gamma$ is the relative risk aversion parameter and $\psi$ measures the elasticity of intertemporal substitution. The linear factor model of Epstein-Zin can be written as:

$$
E\left[R_{t}^{j}-R_{t}^{f}\right]=b_{1} \operatorname{Cov}\left(r_{t}^{m}-r_{t}^{f}, R_{t}^{j}-R_{t}^{f}\right)+b_{2} \operatorname{Cov}\left(\ln \left(\frac{c_{t+1}}{c_{t}}\right), R_{t}^{j}-R_{t}^{f}\right)
$$

where the risk prices are given by

$$
\mathbf{b}=\left[\begin{array}{c}
b_{1} \\
b_{2}
\end{array}\right]=\left[\begin{array}{c}
1-\frac{1-\gamma}{1-1 / \psi} \\
\left(\frac{1-\gamma}{1-1 / \psi}\right) / \psi
\end{array}\right]
$$

Note that this linear factor model can nest the CAPM and the CCAPM (Breeden, 1979; Breeden and Litzenberger, 1978; Rubinstein, 1976) as special cases. When $\psi \rightarrow \infty$, $b_{1}=\gamma$, we have the CAPM. With $\psi=1 / \gamma, b_{1}=0, b_{2}=\gamma$, that is the CCAPM. Namely, the linear factor model of CCAPM can be expressed as

$$
E\left[R_{t}^{j}-R_{t}^{f}\right]=\gamma \operatorname{Cov}\left(\ln \left(\frac{c_{t+1}}{c_{t}}\right), R_{t}^{j}-R_{t}^{f}\right)
$$

\section{Jagannathan and Wang (1996) Human Capital Model}

Jagannathan and Wang (1996) has proposed the conditional CAPM with human capital (HC) as additional factor. Based on equation (C.1), their conditional model has the form of 


$$
\begin{aligned}
\mathbb{E}_{t}\left[R_{t+1}^{j}-R_{t+1}^{f}\right]= & b_{1} \operatorname{Cov}_{t}\left(\operatorname{cay}_{t}, R_{t+1}^{j}-R_{t+1}^{f}\right)+b_{2} \operatorname{Cov}_{t}\left(r_{t+1}^{m}-r_{t+1}^{f}, R_{t+1}^{j}-R_{t+1}^{f}\right) \quad(\mathrm{C} .6) \\
& +b_{3} \operatorname{Cov}_{t}\left(\operatorname{cay}_{t}\left(r_{t+1}^{m}-r_{t+1}^{f}\right), R_{t+1}^{j}-R_{t+1}^{f}\right)+b_{4} \operatorname{Cov}_{t}\left(H C_{t+1}, R_{t+1}^{j}-R_{t+1}^{f}\right) \\
& +b_{5} \operatorname{Cov}_{t}\left(\operatorname{cay}_{t} H C_{t+1}, R_{t+1}^{j}-R_{t+1}^{f}\right)
\end{aligned}
$$




\section{References}

Attanasio, O.P., Weber, G., 1989. Intertemporal substitution, risk aversion and the euler equation for consumption. Economic Journal 99, 59-73.

Bansal, R., Dittmar, R.F., Lundblad, C., 2005. Consumption, dividends, and the crosssection of equity returns. Journal of Finance 60, 1639-1672.

Bansal, R., Yaron, A., 2004. Risks for the long run: a potential resolution of asset pricing puzzles. Journal of Finance 59, 1481-1509.

Boyle, P.P., Ma, C., 2013. w-MPS risk aversion and the CAPM. Theoretical Economics Letters 3, 306-316.

Breeden, D.T., 1979. An intertemporal asset pricing model with stochastic consumption and investment opportunities. Journal of Financial Economics 7, 265-296.

Breeden, D.T., Litzenberger, R.H., 1978. Prices of state-contingent claims implicit in option prices. Journal of Business 51, 621-651.

Campbell, J.Y., 1987. Stock returns and the term structure. Journal of Financial Economics 18, 373-399.

Campbell, J.Y., 1999. Asset prices, consumption, and the business cycle. in Taylor, J., Woodford, M. (Ed.), Handbook of Macroeconomics, Vol. 1, 1231-1303, NorthHolland, Amsterdam.

Campbell, J.Y., Cochrane, J.H., 1999. By force of habit: Consumption-based explanation of aggregate stock market behavior. Journal of Political Economy 107, 205-251.

Campbell, J.Y., Lo, A.W., Mackinlay, A.C., 1997. The Econometrics of Financial Markets. Princeton University Press, Princeton, NJ.

Campbell, J.Y., Shiller, R.J., 1988a. The dividend-price ratio and expectations of future dividends and discount factors. Review of Financial Studies 1, 195-228.

Campbell, J.Y., Shiller, R.J., 1988b. Stock prices, earnings, and expected dividends. Journal of Finance 43, 661-676. 
Campbell, J.Y., Vuolteenaho, T., 2004. Bad beta, good beta. American Economic Review $94,1249-1275$.

Cochrane, J.H., 1996. A cross-sectional test of an investment-based asset pricing model. Journal of Political Economy 104, 572-621.

Constantinides, G.M., Ghosh, A., 2014. Asset pricing with countercyclical household consumption risk. NBER working paper w20110, Cambridge, MA. http://www.nber.org/papers/w20110.

Duffee, G.R., 2005. Time variation in the covariance between stock returns and consumption growth. Journal of Finance 60, 1673-1712.

Epstein, L.G., Zin, S.E., 1989. Substitution, risk aversion and the temporal behavior of consumption and asset returns: a theoretical framework. Econometrica 57, 937-969.

Epstein, L.G., Zin, S.E., 1991. Substitution, risk aversion and the temporal behavior of consumption and asset returns: an empirical analysis. Journal of Political Economy 99, 263-286.

Fama, E.F., French, K.R., 1988. Dividend yields and expected stock returns. Journal of Financial Economics 22, 3-24.

Fama, E.F., French, K.R., 1989. Business conditions and expected returns on stocks and bonds. Journal of Financial Economics 25, 23-49.

Fama, E.F., French, K.R., 1992. The cross-section of expected stock returns. Journal of Finance 47, 427-465.

Fama, E.F., French, K.R., 1993. Common risk factors in the returns on stocks and bonds. Journal of Financial Economics 33, 3-56.

Ferson, W.E., Kandel, S., Stambaugh, R.F., 1987. Tests of asset pricing with timevarying expected risk premiums and market betas. Journal of Finance 42, 201-220.

Guvenen, F., 2006. Reconciling conflicting evidence on the elasticity of intertemporal substitution: a macroeconomic perspective. Journal of Monetary Economics 53, $1451-1472$. 
Hall, R.E., 1988. Intertemporal substitution in consumption. Journal of Political Economy $96,339-357$.

Hansen, L.P., Singleton, K.J., 1982. Generalized instrumental variables estimation of nonlinear rational expectations models. Econometrica 50, 1269-1288.

Harvey, C.R., 1989. Time-varying conditional covariances in tests of asset pricing models. Journal of Financial Economics 24, 289-317.

Jagannathan, R., Wang, Z., 1996. The conditional CAPM and the cross-section of expected returns. Journal of Finance 51: 3-53.

Kang, J., Kim, T.S., Lee, C., 2011. Macroeconomic risk and the cross-section of stock returns. Journal of Banking and Finance 35, 3158-3173.

Keim, D.B., Stambaugh, R.F., 1986. Predicting returns in the stock and bond markets. Journal of Financial Economics 17, 357-390.

Lettau, M., Ludvigson, S., 2001. Consumption, aggregate wealth, and expected stock returns. Journal of Finance 56, 815-849.

Li, G., 2006. Time-varying risk aversion and asset prices. Jounral of Banking and Finance $31,243-257$.

Lucas, R.E., 1978. Asset pricing in an exchange economy. Econometrica 46, 1426-1445.

Ma, C., 2011a. Advanced Asset Pricing Theory. Imperial College Press, London.

Ma, C., 2011b. Continuous time MV analysis in presence of Levy jumps. Risk and Decision Analysis 2, No.4, 221-236.

Markowitz, H., 1959. Portfolio Selection. John Wiley and Sons, New York.

Mehra, R., Prescott, E., 1985. The equity premium puzzle: a puzzle. Journal of Monetary Economics 15, 145-161.

Rubinstein, M., 1976. The valuation of uncertain income streams and the pricing of options. Bell Journal of Economics 7, 407-425.

Santos, T., Veronesi, P., 2006. Labor income and predictable stock returns. Review of Financial Studies 19, 1-44. 
Shiller, R.J., 2005. Irrational Exuberance. 2nd edition, Broadway Books, New York.

Stock, J.H., Watson, M.W., 1989. New indexes of coincident and leading economic indicators. In Blanchard O.J., Fischer, S. (Eds.), NBER Macroeconomics Annual, Vol. 4, 351-409, MIT Press, Cambridge.

Vissing-Jorgensen, A., 2002. Limited asset market participation and the elasticity of intertemporal substitution. Journal of Political Economy 110, 825-853.

Weil, P., 1989. The equity premium puzzle and the risk-free rate puzzle. Journal of Monetary Economics 24, 401-421.

Xiao, Y., Faff, R., Gharghori, P., Min, B., 2013. Pricing innovations in consumption growth: a re-evaluation of the recursive utility model. Journal of Banking and Finance $37,4465-4475$.

Yogo, M., 2006. A consumption-based explanation of expected stock returns. Journal of Finance 61, 539-580. 
Table 1: Estimation of Euler Equation of the Shadow CAPM

\begin{tabular}{|c|c|c|c|c|c|c|}
\hline \multirow{2}{*}{ Panel A: 4 Size Portfolios } & \multicolumn{3}{|c|}{$\mathrm{GDP} / \mathrm{C}$ as $K$} & \multicolumn{3}{|c|}{$(P+D) / D$ as $K$} \\
\hline & & & & & & \\
\hline \multirow{5}{*}{$\begin{array}{l}\text { Elasticity of inter- } \\
\text { temporal substitution }(\psi) \\
J \text {-test }\end{array}$} & $\overline{D E F}$ & $\overline{T R M}$ & cay & $\overline{D E F}$ & $T R M$ & cay \\
\hline & 1.224 & 1.223 & 1.182 & 1.060 & 1.141 & 1.153 \\
\hline & $(13.50)$ & $(21.56)$ & $(13.81)$ & $(47.78)$ & $(16.40)$ & $(2.95)$ \\
\hline & 4.45 & 3.99 & 14.74 & 9.67 & 9.49 & 10.89 \\
\hline & {$[0.88]$} & {$[0.91]$} & {$[0.10]$} & {$[0.38]$} & [0.39] & {$[0.28]$} \\
\hline \multicolumn{7}{|c|}{ Panel B: 6 Portfolios Sorted by Size and Value } \\
\hline \multirow{4}{*}{$\begin{array}{l}\text { Elasticity of inter- } \\
\text { temporal substitution }(\psi) \\
J \text {-test }\end{array}$} & 1.280 & 1.019 & 1.113 & 1.091 & 1.098 & 1.139 \\
\hline & $(16.38)$ & $(4.33)$ & $(6.51)$ & $(5.84)$ & $(4.88)$ & $(7.06)$ \\
\hline & 36.55 & 19.78 & 16.22 & 16.77 & 18.39 & 24.20 \\
\hline & {$[0.00]$} & {$[0.18]$} & {$[0.37]$} & {$[0.33]$} & {$[0.24]$} & {$[0.06]$} \\
\hline \multicolumn{7}{|c|}{ Panel C: 6 Portfolios Sorted by Size and Momentum } \\
\hline \multirow{4}{*}{$\begin{array}{l}\text { Elasticity of inter- } \\
\text { temporal substitution }(\psi) \\
J \text {-test }\end{array}$} & 1.135 & 1.124 & 1.114 & 1.090 & 1.058 & 1.136 \\
\hline & $(4.25)$ & $(8.49)$ & $(10.85)$ & $(3.38)$ & $(18.44)$ & $(2.96)$ \\
\hline & 17.15 & 13.15 & 20.04 & 15.34 & 15.16 & 19.74 \\
\hline & {$[0.31]$} & [0.59] & {$[0.17]$} & {$[0.43]$} & {$[0.44]$} & {$[0.18]$} \\
\hline \multicolumn{7}{|c|}{ Panel D: 10 Industry Portfolios } \\
\hline \multirow{4}{*}{$\begin{array}{l}\text { Elasticity of inter- } \\
\text { temporal substitution }(\psi) \\
J \text {-test }\end{array}$} & 1.088 & 1.134 & 1.139 & 1.212 & 1.209 & 1.126 \\
\hline & $(9.89)$ & $(13.97)$ & $(15.56)$ & $(5.99)$ & $(5.60)$ & $(6.13)$ \\
\hline & 27.69 & 38.54 & 35.22 & 72.98 & 51.27 & 49.55 \\
\hline & {$[0.43]$} & {$[0.07]$} & {$[0.13]$} & {$[0.00]$} & {$[0.00]$} & {$[0.00]$} \\
\hline
\end{tabular}

We use two measures for wealth-dividend ratio: GDP/C and $(\mathrm{P}+\mathrm{D}) / \mathrm{D}$. The test assets in Panel A are the first, second, fifth and tenth decile portfolios sorted by size. The test assets in Panel B are six portfolios sorted by size and book-to-market equity. The six portfolios sorted by size and momentum are the test assets in Panel C. Panel D shows the estimation results for 10 industry portfolios. Three sets of instrumental variables from left to right: default premium, term premium and cay, all of them with a constant and dividend-price ratio. Estimation is done by two-step GMM. $t$-statistics are in parentheses. The $p$-values for $J$-test of overidentifying restrictions are in brackets. 
Table 2: Estimation of Linear Factor Models

\begin{tabular}{|c|c|c|c|c|c|c|}
\hline \multirow[t]{2}{*}{$\begin{array}{l}\text { Factor Price } \\
\text { Specification }\end{array}$} & \multirow[t]{2}{*}{ CAPM } & \multirow[t]{2}{*}{$\begin{array}{l}\text { Fama-French } \\
\text { eq (C.3) }\end{array}$} & \multirow[t]{2}{*}{$\begin{array}{l}\text { CCAPM } \\
\text { eq (C.5) }\end{array}$} & \multirow[t]{2}{*}{$\begin{array}{l}\text { Epstein-Zin } \\
\text { eq (C.4) }\end{array}$} & \multicolumn{2}{|c|}{$\begin{array}{c}\text { Shadow CAPM } \\
\text { eq (8) }\end{array}$} \\
\hline & & & & & $(\mathrm{P}+\mathrm{D}) / \mathrm{D}$ & GDP/C \\
\hline Market & $\begin{array}{l}2.396 \\
(2.72)\end{array}$ & $\begin{array}{l}3.357 \\
(3.41)\end{array}$ & & $\begin{array}{l}10.126 \\
(7.07)\end{array}$ & $\begin{array}{l}1.833 \\
(1.94)\end{array}$ & $\begin{array}{l}4.296 \\
(2.54)\end{array}$ \\
\hline SMB & & $\begin{array}{l}1.950 \\
(1.41)\end{array}$ & & & & \\
\hline HML & & $\begin{array}{l}8.642 \\
(5.09)\end{array}$ & & & & \\
\hline $\begin{array}{l}\text { Consumption } \\
\text { growth }\end{array}$ & & & $\begin{array}{c}234.250 \\
(3.28)\end{array}$ & $\begin{array}{l}76.912 \\
(3.23)\end{array}$ & & \\
\hline $\begin{array}{l}\text { Wealth-dividend } \\
\text { ratio }\end{array}$ & & & & & $\begin{array}{l}-1.379 \\
(-4.44)\end{array}$ & $\begin{array}{r}-19.317 \\
(-4.57)\end{array}$ \\
\hline MAE $(\%)$ & 0.204 & 0.120 & 0.222 & 0.187 & 0.180 & 0.173 \\
\hline $\operatorname{adj}-R^{2}$ & -0.44 & 0.42 & -0.18 & -0.30 & 0.13 & 0.21 \\
\hline J-test & $\begin{array}{l}115.18 \\
{[0.00]}\end{array}$ & $\begin{array}{c}100.84 \\
{[0.00]}\end{array}$ & $\begin{array}{l}103.09 \\
{[0.00]}\end{array}$ & $\begin{array}{c}209.90 \\
{[0.00]}\end{array}$ & $\begin{array}{l}55.67 \\
{[0.00]}\end{array}$ & $\begin{array}{l}40.53 \\
{[0.01]}\end{array}$ \\
\hline
\end{tabular}

The test assets are the 25 Fama-French portfolios sorted by size and book-to-market equity. Estimation is by two-step GMM. The mean absolute pricing error (MAE) and adj- $\mathrm{R}^{2}$ are based on the first-stage estimate. Adj- $\mathrm{R}^{2}$ is following Campbell and Vuoleenaho's (2004) definition, which is calculated as one minus the mean square pricing error to the variance of average portfolio returns. $t$-statistics are in parentheses and the $p$-values for the $J$-test are in brackets. 
Table 3: Estimation Results for Conditional Linear Factor Models

\begin{tabular}{lcccc}
\hline Factor Price & CAPM & CCAPM & Epstein-Zin & $\begin{array}{c}\text { Human Capital } \\
\text { eq(C.6) }\end{array}$ \\
\hline cay & 29.801 & 63.860 & 32.265 & -32.648 \\
& $(3.13)$ & $(3.61)$ & $(2.02)$ & $(-2.11)$ \\
Market & 6.285 & & 0.274 & 6.905 \\
& $(7.97)$ & & $(0.49)$ & $(5.54)$ \\
Market • cay & -303.170 & & -17.896 & 491.006 \\
& $(-2.75)$ & & $(-0.16)$ & $(3.18)$ \\
Consumption growth & & 57.500 & 35.246 & \\
& & $(2.90)$ & $(1.97)$ & \\
Consumption growth · cay & & -1199.968 & -20.415 & \\
& & $(-0.54)$ & $(-0.01)$ & \\
Human Capital & & & & 64.051 \\
& & & & $(2.22)$ \\
Human Capital · cay & & & & -297.431 \\
MAE(\%) & & & & $(-0.16)$ \\
adj- $R^{2}$ & 0.179 & 0.188 & 0.219 & 0.211 \\
J-test & -0.11 & -0.13 & -0.43 & -0.35 \\
& 56.83 & 84.18 & 44.30 & 46.60 \\
\hline
\end{tabular}

The test assets are the 25 Fama-French portfolios sorted by size and book-to-market equity. Estimation is by two-step GMM. The mean absolute pricing error (MAE) and adj- $\mathrm{R}^{2}$ are based on the first-stage estimate. Adj- $\mathrm{R}^{2}$ is following Campbell and Vuoleenaho's (2004) definition, which is calculated as one minus the mean square pricing error to the variance of average portfolio returns. $t$-statistics are in parentheses and the $p$-values for the $J$-test are in brackets. 
Table 4: Average Returns and Shadow Risk Premiums for the Fama-French Portfolios

\begin{tabular}{|c|c|c|c|c|c|c|}
\hline \multirow[b]{2}{*}{ Size } & \multicolumn{6}{|c|}{ Book-to-Market Equity } \\
\hline & Low & 2 & 3 & 4 & High & High-Low \\
\hline \multicolumn{7}{|c|}{ Panel A: Average Excess Return (\%) } \\
\hline Small & 0.018 & 0.614 & 0.703 & 0.964 & 1.032 & 1.014 \\
\hline 2 & 0.187 & 0.573 & 0.794 & 0.862 & 0.950 & 0.763 \\
\hline 3 & 0.328 & 0.640 & 0.673 & 0.831 & 0.884 & 0.556 \\
\hline 4 & 0.425 & 0.491 & 0.743 & 0.758 & 0.765 & 0.339 \\
\hline Big & 0.420 & 0.465 & 0.555 & 0.542 & 0.548 & 0.128 \\
\hline Small-Big & -0.402 & 0.149 & 0.148 & 0.422 & 0.484 & \\
\hline \multicolumn{7}{|c|}{ Panel B: $\alpha_{\Lambda}^{j}$ in shadow CAPM equation (5) } \\
\hline Small & 3.004 & 2.612 & 2.304 & 2.163 & 2.298 & -0.706 \\
\hline 2 & 2.940 & 2.481 & 2.241 & 2.174 & 2.389 & -0.551 \\
\hline 3 & 2.805 & 2.358 & 2.156 & 2.082 & 2.210 & -0.595 \\
\hline 4 & 2.593 & 2.300 & 2.202 & 2.071 & 2.255 & -0.338 \\
\hline Big & 2.162 & 2.018 & 1.882 & 1.840 & 1.976 & -0.186 \\
\hline Small-Big & 0.842 & 0.594 & 0.422 & 0.323 & 0.322 & \\
\hline \multicolumn{7}{|c|}{ Panel C: $\gamma_{\Lambda}^{j}$ in equation (5) with $\mathrm{K}=(\mathrm{P}+\mathrm{D}) / \mathrm{D}$} \\
\hline Small & 0.005 & 1.301 & 1.595 & 3.050 & 3.777 & 3.772 \\
\hline 2 & 0.348 & 1.233 & 1.539 & 2.821 & 3.036 & 2.688 \\
\hline 3 & 0.516 & 1.260 & 1.450 & 2.064 & 2.116 & 1.601 \\
\hline 4 & 0.865 & 1.245 & 1.475 & 1.253 & 1.271 & 0.406 \\
\hline Big & 1.010 & 1.154 & 1.193 & 1.453 & 1.253 & 0.242 \\
\hline Small-Big & -1.005 & 0.147 & 0.402 & 1.597 & 2.524 & \\
\hline \multicolumn{7}{|c|}{ Panel D: $\gamma_{\Lambda}^{j}$ in equation (5) with $\mathrm{K}=\mathrm{GDP} / \mathrm{C}$} \\
\hline Small & 0.117 & 2.184 & 2.949 & 2.958 & 3.481 & 3.364 \\
\hline 2 & 0.510 & 1.743 & 2.608 & 2.648 & 3.025 & 2.516 \\
\hline 3 & 1.110 & 1.887 & 2.961 & 2.809 & 2.960 & 1.850 \\
\hline 4 & 1.251 & 1.460 & 2.069 & 2.032 & 2.586 & 1.335 \\
\hline Big & 1.211 & 1.243 & 2.003 & 2.496 & 2.262 & 1.051 \\
\hline Small-Big & -1.094 & 0.941 & 0.946 & 0.462 & 1.219 & \\
\hline
\end{tabular}

Panel A reports average excess returns on the 25 Fama-French portfolios sorted by size and book-to-market equity. Panel B reports the unconditional $\alpha_{\Lambda}^{j}$ in equation (5). Panels $\mathrm{C}$ and $\mathrm{D}$ report the unconditional $\gamma_{\Lambda}^{j}$, for the two different wealth-dividend ratio measures. The results are calculated by setting $\psi$ to the average value in Table 1 . 
Table 5: Linear Factor Model with Unconditional Covariance

\begin{tabular}{cccc}
\hline Factor Price & $(P+D) / D$ & GDP $/ \mathrm{C}$ & $\mathrm{ME} / \mathrm{C}$ \\
\hline Market & 3.435 & 4.079 & 5.613 \\
& $(2.51)$ & $(2.42)$ & $(3.46)$ \\
Wealth-dividend ratio & -1.668 & -9.484 & -1.197 \\
& $(-4.33)$ & $(-2.52)$ & $(-2.71)$ \\
$J$-test & 7.36 & 14.27 & 10.32 \\
& {$[0.69]$} & {$[0.16]$} & {$[0.41]$} \\
\hline
\end{tabular}

The estimation is based on the unconditional linear factor model of the shadow CAPM (equation (8)) with instrumental variables. The test assets are the first, second, fifth and tenth decile portfolios sorted by size. The instrumental variables are the term premium, the dividend-price ratio and a constant. Estimation is by two-step GMM. $t$-statistics are in parentheses. The $p$-values for the $J$-test are in brackets.

Table 6: Linear Factor Model with Conditional Covariance

\begin{tabular}{cccc}
\hline Factor Price & $(P+D) / D$ & GDP $/ \mathrm{C}$ & $\mathrm{ME} / \mathrm{C}$ \\
\hline Market & 5.082 & 3.608 & 6.649 \\
& $(3.51)$ & $(2.45)$ & $(3.35)$ \\
Wealth-dividend ratio & -12.012 & -108.74 & -3.721 \\
& $(-2.79)$ & $(-3.30)$ & $(-2.33)$ \\
$J$-test & 20.06 & 18.18 & 16.89 \\
& {$[0.58]$} & {$[0.69]$} & {$[0.77]$} \\
\hline
\end{tabular}

This table and Table 7 report estimates of the conditional linear factor model of the shadow CAPM, i.e. equations (10) and (11). This table reports the estimates of the risk prices $b_{1}$ for the market, and $b_{2}$ for the wealth dividend ratio. The test assets are the first, second, fifth and tenth decile portfolios sorted by size. The instrumental variables are the term premium, the dividend-price ratio and a constant. Estimation is by two-step GMM. t-statistics are in parentheses. The $p$-values for the $J$-test of overidentifying restrictions are in brackets. 
Table 7: Expected Return and Conditional Covariance

\begin{tabular}{ccccc}
\hline Instrument & Portfolio 1 & Portfolio 2 & Portfolio 5 & Portfolio 10 \\
\hline \multicolumn{5}{c}{ Panel A: Expected Return } \\
\hline TRM & 0.476 & 0.422 & 0.407 & 0.283 \\
& $(2.47)$ & $(2.20)$ & $(2.37)$ & $(2.14)$ \\
D/P & 0.367 & 0.410 & 0.441 & 0.298 \\
& $(1.85)$ & $(2.07)$ & $(2.49)$ & $(2.18)$ \\
\hline Panel B: Covariance with & Wealth-Dividend Ratio: & $(P+D) / D$ \\
\hline TRM & -3.154 & -3.307 & -3.101 & -2.469 \\
& $(-2.01)$ & $(-2.23)$ & $(-2.24)$ & $(-2.18)$ \\
D/P & -3.226 & -3.943 & -3.812 & -2.472 \\
& $(-1.81)$ & $(-2.30)$ & $(-2.42)$ & $(-2.10)$ \\
\hline Panel C: Covariance with Wealth-Dividend Ratio: GDP/C \\
\hline TRM & -0.579 & -0.522 & -0.517 & -0.273 \\
& $(-3.01)$ & $(-2.92)$ & $(-3.10)$ & $(-2.34)$ \\
D/P & -0.572 & -0.672 & -0.660 & -0.407 \\
& $(-2.10)$ & $(-2.47)$ & $(-2.58)$ & $(-2.17)$ \\
\hline Panel D: Covariance with Wealth-Dividend Ratio: & ME/C \\
\hline TRM & -10.345 & -11.277 & -10.667 & -8.197 \\
& $(-2.03)$ & $(-2.24)$ & $(-2.24)$ & $(-2.03)$ \\
D/P & -8.590 & -11.590 & -11.886 & -8.156 \\
& $(-1.32)$ & $(-1.77)$ & $(-1.91)$ & $(-1.76)$ \\
\hline
\end{tabular}

This table reports the estimation results of equation (10) in Panel A. Panels B to D report the estimation results of equation (11). The instrumental variables are the term premium (TRM), the dividend-price ratio $(\mathrm{D} / \mathrm{P})$ and a constant. t-statistics are in parentheses. 

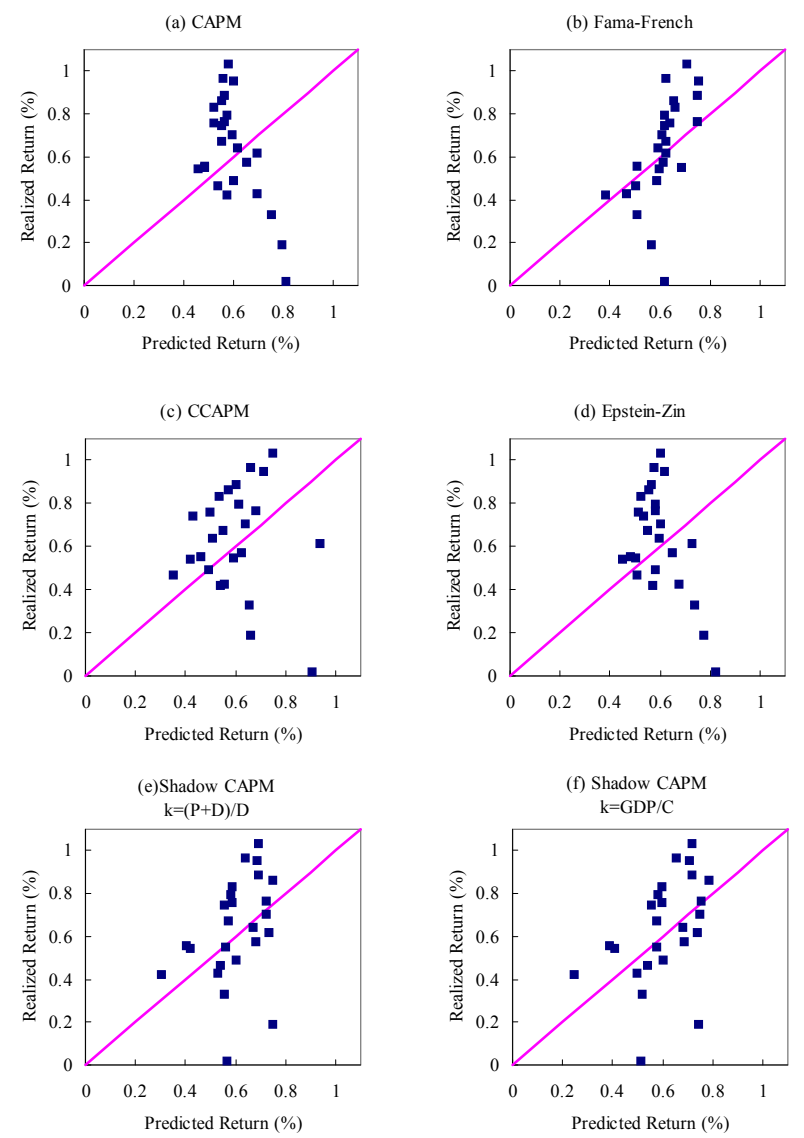

Figure 1: Realized v.s. Predicted Excess Returns for the Fama-French Portfolios in the Unconditional Models. The figure plots realized versus predicted excess returns (per month) for the 25 Fama-French portfolios sorted by size and book-to-market equity implied from the unconditional models. The vertical distance to the 45-degree line represents the pricing error of the portfolios. 
(a) Conditional CAPM

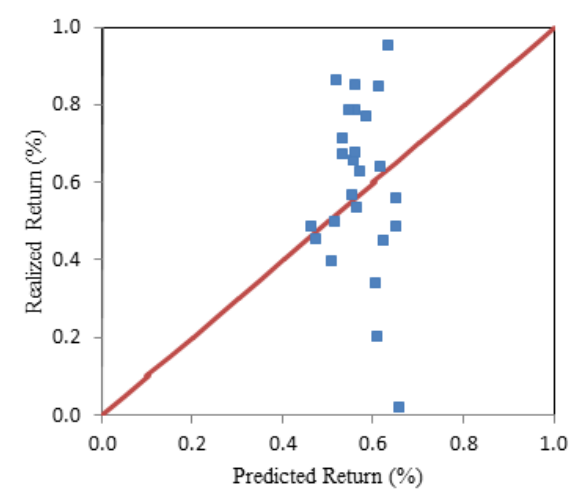

(c) Conditional Epstein-Zin

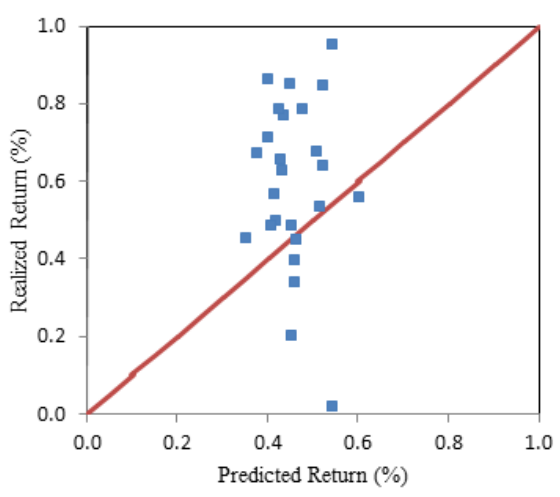

(b) Conditional CCAPM

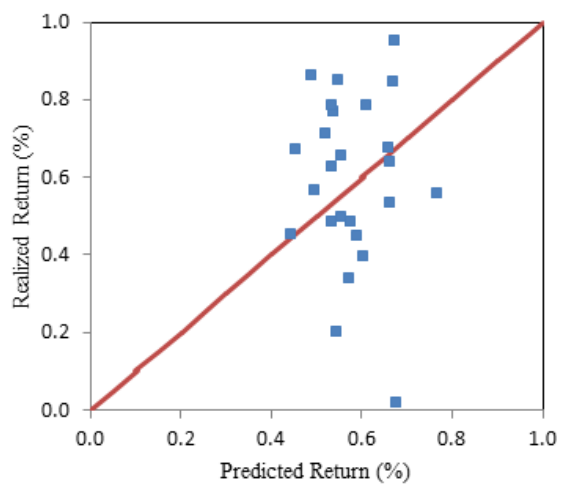

(d) Jagannathan-Wang Model

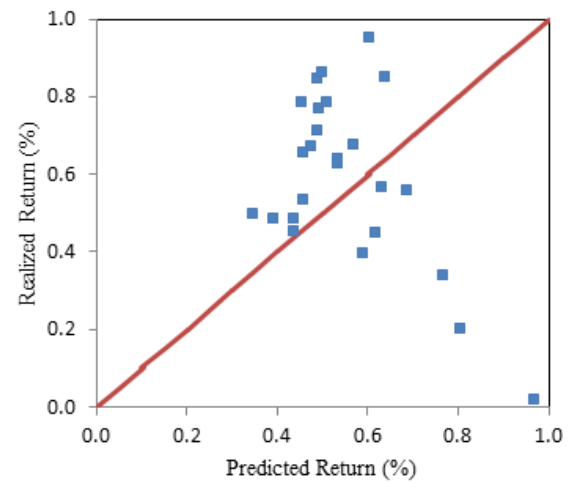

Figure 2: Realized v.s. Predicted Excess Returns for the Fama-French Portfolios in the Conditional Models. The figure plots realized versus predicted excess returns (per month) for the 25 Fama-French portfolios sorted by size and book-to-market equity implied from the conditional models. The vertical distance to the 45-degree line represents the pricing error of the portfolios. 


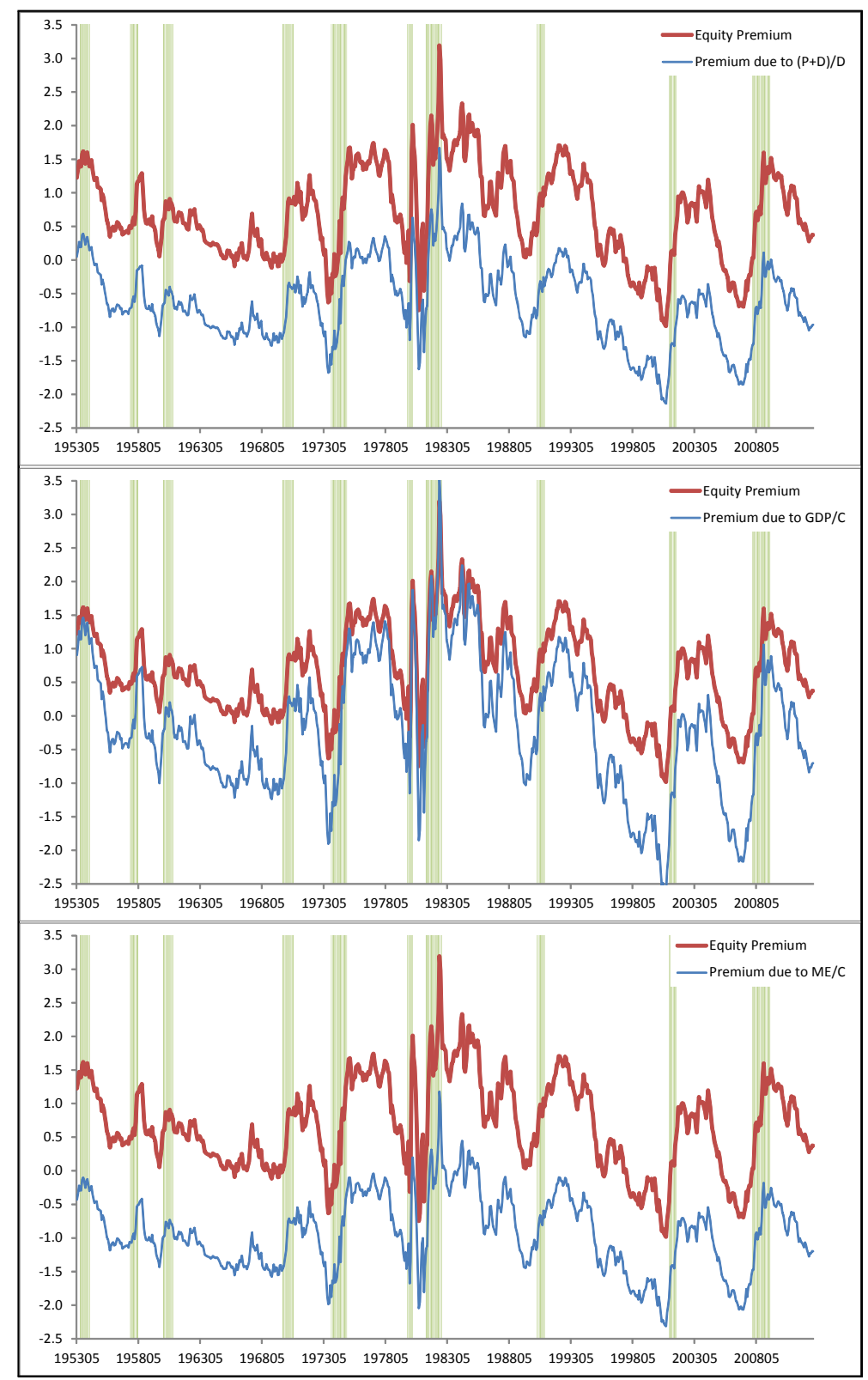

Figure 3: Time Variation in the Equity Premium. The figure is a time-series plot of expected excess returns on the fifth size portfolio. Each panel corresponds to the three specifications on wealth-dividend ratio: $(\mathrm{P}+\mathrm{D}) / \mathrm{D}, \mathrm{GDP} / \mathrm{C}$ and $\mathrm{ME} / \mathrm{C}$. The shaded regions are NBER recessions. 